\title{
Synergistic enhancement of gas selectivity in thin film composite membranes of PIM-1
}

DOI:

10.1039/C8TA10691F

Document Version

Accepted author manuscript

Link to publication record in Manchester Research Explorer

\section{Citation for published version (APA):}

Borisov, I. L., Bakhtin, D. S., Luque-alled, J. M., Rybakova, A., Makarova, V., Foster, A. B., Harrison, W., Volkov, V. V., Polevaya, V., Gorgojo, P., Prestat, E., Budd, P. M., \& Volkov, A. V. (2019). Synergistic enhancement of gas selectivity in thin film composite membranes of PIM-1. Journal of Materials Chemistry A.

https://doi.org/10.1039/C8TA10691F

Published in:

Journal of Materials Chemistry A

\section{Citing this paper}

Please note that where the full-text provided on Manchester Research Explorer is the Author Accepted Manuscript or Proof version this may differ from the final Published version. If citing, it is advised that you check and use the publisher's definitive version.

\section{General rights}

Copyright and moral rights for the publications made accessible in the Research Explorer are retained by the authors and/or other copyright owners and it is a condition of accessing publications that users recognise and abide by the legal requirements associated with these rights.

\section{Takedown policy}

If you believe that this document breaches copyright please refer to the University of Manchester's Takedown Procedures [http://man.ac.uk/04Y6Bo] or contact uml.scholarlycommunications@manchester.ac.uk providing relevant details, so we can investigate your claim.

\section{OPEN ACCESS}




\title{
Synergistic enhancement of gas selectivity in thin film composite membranes of PIM-1
}

\author{
Ilya Borisov ${ }^{\mathrm{a}}$, Danila Bakhtin ${ }^{\mathrm{a}}$, Jose M. Luque-Alled ${ }^{\mathrm{b}}$, Anastasiya Rybakova ${ }^{\mathrm{a}}$, Veronika \\ Makarova a , Andrew B. Foster ${ }^{\mathrm{c}}$, Wayne J. Harrison ${ }^{\mathrm{c}}$, Vladimir Volkov ${ }^{\mathrm{a}}$, Viktoria Polevaya ${ }^{\mathrm{a}}$, \\ Patricia Gorgojo $^{\mathrm{b}}$, Eric Prestat ${ }^{\mathrm{d}, \mathrm{e}}$, Peter M. Budd ${ }^{\mathrm{c}}$, Alexey Volkov* ${ }^{\mathrm{a}}$
}

a. A.V.Topchiev Institute of Petrochemical Synthesis RAS, Moscow, 119991, Russia. Email: avolkov@ips.ac.ru

b. School of Chemical Engineering and Analytical Science, The University of Manchester, Manchester, M13 9PL, UK.

c. School of Chemistry, The University of Manchester, Manchester, M13 9PL, UK.

d. School of Materials, The University of Manchester, Manchester, M13 9PL, UK.

e. SuperSTEM Laboratory, SciTech Daresbury Campus, Daresbury, WA4 4AD, UK.

\begin{abstract}
High free volume glassy polymers or polymers of intrinsic microporosity such as poly[1trimethylsilyl-1-propyne] (PTMSP) and polybenzodioxane (PIM-1) are extra high gas permeability membrane materials. One of their major drawbacks is low gas selectivity. In this study, thin film composite (TFC) membranes have been developed with high $\mathrm{CO}_{2}$ permeance and superior $\mathrm{CO}_{2} / \mathrm{N}_{2}$ selectivity due to a strong synergistic effect. The TFC membranes, comprising a thin layer (0.29-0.42 $\mu \mathrm{m})$ of PIM-1 atop a cross-linked PTMSP gutter layer $(2.07-3.44 \mu \mathrm{m})$ on a porous backing material, were fabricated by coating PIM-1 solution on the cross-linked PTMSP support. A key element is that for coating PIM-1 a mixed solvent of chloroform and trichloroethylene (1:1) was successfully implemented for the first time. All membrane samples demonstrated a strong synergistic enhancement of $\mathrm{CO}_{2} / \mathrm{N}_{2}$ selectivity ( $\left.\alpha=35.8-55.7\right)$ compared to PIM- $(\alpha=18.5)$ and cross-linked PTMSP $(\alpha=3.7)$. SEM, TEM and laser interferometry studies revealed that the synergistic enhancement of gas selectivity in the TFC membranes is most likely due to the creation of a very thin boundary layer between PIM-1 and the cross-linked PTMSP gutter layer. The aged TFC membranes (after three months) showed a severe drop in gas permeance while keeping nearly the same high selectivity. Thus, future success in the prevention of polymer physical aging, together with the synergy effect in selectivity reported for the first time in this work, will give new opportunities for application of polymers of intrinsic microporosity.
\end{abstract}

\section{Introduction}

High free volume glassy polymers such as substituted polyacetylenes, polynorbornenes or polybenzodioxanes are attractive membrane materials for gas separation due to their high masstransfer parameters together with good mechanical and film-forming properties. ${ }^{1-7}$ One of the major drawbacks of these highly permeable glassy polymers is rather low gas selectivity, since the interconnected free volume elements with a size of about 0.4-1.2 nm play a major role in the gas transport through the membrane. The intrinsic microporous structure can provide additional selectivity in favor of a condensable gas as a result of the "blocking" effect of the free volume elements by bigger gas molecules (e.g., separation of $n$-butane/methane mixture with PTMSP or PIM1) ${ }^{8-10}$ Nevertheless, gas separation membranes solely made of the first and second generations of polymers of intrinsic microporosity (PIMs) are limited by their low selectivity, although these glassy polymers can be considered as useful polymeric matrices for development of promising composite materials for gas separation thanks to their high gas transport characteristics, close to the Robeson upper bound. ${ }^{5,11}$ The combination of permeability and selectivity can be adjusted, for example, by (i) 
incorporation of different types of additives having porous or non-porous and organic or inorganic nature, ${ }^{12-20}$ (ii) molecular design by varying, for example, number of $\mathrm{Si}\left(\mathrm{CH}_{3}\right)_{3}$ or $\mathrm{CF}_{3}$ groups, ${ }^{21-23}$ or (iii) blending with other polymers. ${ }^{24-26}$ In some cases, mixed matrix materials with restricted mobility of the macromolecular chains as a result of chemical or physical cross-linking can possess improved long-term stability against physical aging compared with the virgin high free volume glassy polymers. ${ }^{17-19,27-29}$

The desired combination of gas permeance and selectivity can be achieved by casting a very thin layer of highly selective membrane material on a porous support to give a thin film composite (TFC) membrane. To maintain the mechanical strength of the selective layer during operation at a certain trans-membrane pressure difference, the typical support has pores within the ultrafiltration range that dramatically reduce the surface porosity. For post-combustion carbon capture, it was shown that the gas separation method could be effectively applied for treatment of a large amount of flue gas if the membrane possesses $\mathrm{CO}_{2}$ permeance above 1000 GPU and $\mathrm{CO}_{2} / \mathrm{N}_{2}$ selectivity above $20 .^{30}$ In principle, the PIM-1 material, with $\mathrm{CO}_{2} / \mathrm{N}_{2}$ selectivity in the region 18-20, is close to what is required for $\mathrm{CO}_{2}$ transport if it is operated as a thin selective layer. However, it has been pointed out that the performance of TFC membranes can be limited not only by the selective layer but also by the gas permeance of the support. ${ }^{31}$ For instance, it was demonstrated that for a TFC membrane with a $100 \mathrm{~nm}$ top-layer its $\mathrm{CO}_{2}$ permeance and $\mathrm{CO}_{2} / \mathrm{N}_{2}$ selectivity would decline by about a factor of seven if the performance of the support layer changes from $10^{5}$ down to $10^{3}$ GPU. Such dramatic changes can be explained by the fact that the diffusion path of gas molecules within the very thin polymeric layer towards the pores in the support might exceed the thickness of the selective layer.

The transport performance of TFC membranes can be improved by the introduction of a gutter layer, based on a high free volume glassy polymer, between the thin top-layer and the porous support. ${ }^{32-34}$ The main function of this intermediate layer is to provide effective vertical and tangential evacuation of the gas molecules from the backside of the selective layer to the pores of the support. In particular, it was shown ${ }^{32}$ that the use of such an intermediate (gutter) layer made of cross-linked poly[1-trimethylsilyl-1-propyne] (PTMSP) between a polyacrylonitrile porous support with $\mathrm{N}_{2}$ permeability of $85 \mathrm{~m}^{3} /\left(\mathrm{m}^{2} \cdot \mathrm{h} \cdot \mathrm{bar}\right)$ and a selective layer based on modified Matrimid 5218 provided simultaneous enhancement in gas fluxes and selectivity.

Since the support layer plays a role in the mass-transfer resistance, the overall performance of TFC membranes can be further improved by using a microfiltration rather than ultrafiltration support. For instance, a composite membrane with a cross-linked PTMSP layer of 1-2.5 $\mu \mathrm{m}$, insoluble in chloroform, on top of MFFK-1 (microfiltration support; $\mathrm{N}_{2} 180000 \mathrm{GPU}$ ) demonstrated $\mathrm{CO}_{2}$ permeance of $50-54 \mathrm{~m}^{3} /\left(\mathrm{m}^{2} \cdot \mathrm{h} \cdot \mathrm{bar}\right)(\sim 180000-200000$ GPU) and ideal $\mathrm{CO}_{2} / \mathrm{N}_{2}$ selectivity of 3.6-3.7. ${ }^{33}$ For PAN/PSS (ultrafiltration support; $\mathrm{N}_{2}$ permeability of 85 $\mathrm{m}^{3} /\left(\mathrm{m}^{2} \cdot \mathrm{h} \cdot\right.$ bar $)$ ), the composite membrane with a cross-linked PTMSP (x-PTMSP) layer of $0.91 \mu \mathrm{m}$ showed $\mathrm{CO}_{2}$ permeance of $2.6 \mathrm{~m}^{3} /\left(\mathrm{m}^{2} \cdot \mathrm{h} \cdot\right.$ bar $)$ and ideal $\mathrm{CO}_{2} / \mathrm{N}_{2}$ selectivity of $10.3 .^{32}$

The goal of this study was to develop highly permeable composite membranes with $\mathrm{CO}_{2}$ permeance above 1000 GPU and $\mathrm{CO}_{2} / \mathrm{N}_{2}$ selectivity above 20 to match the optimal membrane characteristics for post-combustion $\mathrm{CO}_{2}$ capture. ${ }^{30}$ The proposed concept is based on the casting of a selective layer of PIM-1 on top of recently developed high flux supports based on MFFK-1/x-PTMSP. A similar approach was successfully utilized for the development of composite membranes for a high pressure/temperature membrane gas desorption process, where the selective layer consisted of two thin layers of PTMSP with different cis/trans ratio. ${ }^{35}$ For the gas separation membrane, it was decided to use a highly permeable support comprising a cross-linked PTMSP (x-PTMSP) gutter layer on top of microfiltration support MFFK $-1 ;{ }^{33}$ while the desired $\mathrm{CO}_{2} / \mathrm{N}_{2}$ selectivity, with some decline in $\mathrm{CO}_{2}$ permeance, would be achieved by the deposition of a thin top-layer of PIM-1. 


\section{Experimental part}

\subsection{Fabrication of thin-film composite membranes}

Polymer of intrinsic microporosity PIM-1 $\left(M_{\mathrm{w}}=270000 \mathrm{~g} / \mathrm{mol} ; M_{\mathrm{w}} / M_{\mathrm{n}}=2.8\right)^{36}$ ] was dissolved in chloroform at a concentration of 0.5 wt. $\%$. A 0.5 wt.\% solution of PIM-1 in a mixture of solvents, chloroform/trichloroethylene $(1: 1)$, was also prepared. Some physicochemical properties of the solvents are presented in Table 1. All casting solutions were filtered through filter paper (pore size of 5-8 $\mu \mathrm{m}$ ) prior to casting. A recently developed highly permeable support consisting of a commercial microfiltration membrane MFFK-1 (producer "Vladipor", Russia) and a gutter layer of cross-linked PTMSP was selected due to its high $\mathrm{CO}_{2}$ permeance of $50-54 \mathrm{~m}^{3} /\left(\mathrm{m}^{2} \cdot \mathrm{h} \cdot \mathrm{bar}\right)(\sim 180000-200000$ GPU $)^{33}$. The PIM-1 selective layer was deposited on top of the gutter layer by the "kiss-coating" method (coating speed of $1.2 \mathrm{~m} / \mathrm{min}$ ) as described elsewhere ${ }^{33}$. The TFC membranes obtained were dried for at least $24 \mathrm{~h}$ at ambient conditions covered with the filter-paper. The membrane samples were cut into discs with a diameter of $60 \mathrm{~mm}$ for gas permeation tests. The samples were initially tested within 1-2 days after their fabrication, and were tested again after three months to check the effect of physical aging.

Table 1 Some physicochemical properties of solvents used

\begin{tabular}{|c|c|c|c|c|c|c|c|}
\hline \multirow{2}{*}{ Solvent } & \multirow{2}{*}{ Formula } & \multirow{2}{*}{$\begin{array}{l}\text { Viscosity } \\
@ 25^{\circ} \mathrm{C} \text {, } \\
\mathrm{mPa} \cdot \mathrm{s}\end{array}$} & \multirow{2}{*}{$\begin{array}{l}\text { Density, } \\
\mathrm{g} / \mathrm{cm}^{3}\end{array}$} & \multirow{2}{*}{$\begin{array}{l}\text { Boiling } \\
\text { point, }{ }^{\circ} \mathrm{C}\end{array}$} & \multicolumn{3}{|c|}{ Solubility parameter, $\mathrm{MPa}^{0.5}$} \\
\hline & & & & & $\delta_{\mathrm{d}}$ & $\delta_{\mathrm{p}}$ & $\delta_{\mathrm{h}}$ \\
\hline Chloroform & $\mathrm{CHCl}_{3}$ & 0.54 & 1.49 & 61.2 & 17.8 & 3.1 & 5.7 \\
\hline Trichloroethylene & $\mathrm{C}_{2} \mathrm{HCl}_{3}$ & 0.53 & 1.46 & 87.2 & 18.0 & 3.1 & 5.3 \\
\hline
\end{tabular}

\subsection{Solvent evaporation rate from PIM-1 solutions}

The $0.5 \%$ PIM-1 solution of the volume sufficient to obtain a $20 \mu \mathrm{m}$ film was poured into a Petri dish, placed on a microbalance, and allowed to evaporate freely at ambient conditions. The total time of evaporation was about 100 and 250 minutes for chloroform and chloroform/ trichloroethylene solutions, respectively.

\subsection{Fabrication of PIM-1 based dense membranes}

PTMSP/PIM-1 blend membranes were obtained by casting polymer solutions on cellophane and drying at ambient temperature for at least $200 \mathrm{~h}$. Solutions of PIM-1 $\left(M_{\mathrm{w}}=270000 \mathrm{~g} / \mathrm{mol} ; M_{\mathrm{w}} / M_{\mathrm{n}}=2.8\right)$ and PTMSP $\left(M_{\mathrm{w}}=900000 \mathrm{~g} / \mathrm{mol}\right)^{37}$ in chloroform $(0.5 \mathrm{wt}$. \%) were mixed to obtain the desired PIM1/PTMSP ratio; then the casting solution was stirred for at least 1 hour before membrane casting. Using the same technique, blends of PTMSP with cyclic $\left(M_{\mathrm{w}}=8100 \mathrm{~g} / \mathrm{mol} ; M_{\mathrm{w}} / M_{\mathrm{n}}=1.30\right)$ or linear $\left(M_{\mathrm{w}}=12300 \mathrm{~g} / \mathrm{mol} ; M_{\mathrm{w}} / M_{\mathrm{n}}=1.62\right)$ PIM-1 oligomers were fabricated. The thicknesses of all blend films were in the range of $25-30 \mu \mathrm{m}$.

\subsection{Gas permeation experiments}

Gas permeation tests were carried out at room temperature $\left(24 \pm 2{ }^{\circ} \mathrm{C}\right)$ and pressures up to 3 bar with a set-up described elsewhere. ${ }^{38}$ Pure nitrogen and carbon dioxide gases (both are 99.9\% purity) were used. The gas flux $J$ at constant pressure $p$ was estimated by the volumetric method according to the following equation:

$$
J_{\text {gas }}=\frac{V}{S t}
$$

where $V$ is the volume of the gas passing through the membrane with active area $S\left(12.56 \mathrm{~cm}^{2}\right)$ per unit of time $t$. The pressure-normalized flux or gas permeance was calculated from the slope of the $J-p$ curve as follows: 


$$
P_{\text {gas }} /_{l}=J_{\text {gas }} / \Delta p
$$

where $\Delta p$ is the transmembrane pressure and $l$ is the thickness of the selective layer.

\subsection{Scanning electron microscopy}

The morphology of TFC membranes was studied by high-resolution SEM on a Hitachi TM3030Plus tabletop microscope. To prepare membrane cleavages, the membranes were preliminarily impregnated in isopropanol and then broken in a liquid nitrogen medium. Using a DSR-1 table spraying gun (Nanostructured Coatings Co.), the prepared samples were coated with a thin (5 $\mathrm{nm}$ thick) layer of gold in a special chamber under vacuum (about 50 torr).

\subsection{Transmission electron microscopy}

In order to establish the thicknesses of the gutter layer and PIM layer, the cross-section specimens of TFC membranes based on PIM-1 were imaged using a Tecnai G2 20 transmission electron microscope operating at $200 \mathrm{kV}$ and equipped with an Oxford Instruments X-Max windowless EDS detector. For sub-nanometer resolution elemental mapping, scanning transmission electron microscopy high angle annular dark field (STEMHAADF) and electron energy loss spectroscopy (EELS) were performed using a FEI Titan ChemiSTEM 80-200 fitted with probe-side aberration corrector, a GIF Quantum ER and an $\mathrm{X}$-FEG electron source operating at $200 \mathrm{kV}$. TEM specimens were prepared by the ultramicrotomy method. First, the TFC samples were immersed in a resin mixture (Araldite resin AY103-1 and Aradur hardener HY951, ratio 1:1) and left to dry under $\mathrm{N}_{2}$ flow for 24 hours at room temperature. Ultrathin sections, around $100 \mathrm{~nm}$, of the TFC sample embedded in the resin were obtained using an ultracut E ultramicrotome (Reichert-Jung, USA). The cross section specimens were cut using a diamond knife (DiATOME, Switzerland) which was positioned perpendicular to the face of the membrane. A cutting angle of $6^{\circ}$ and speed of 1 $\mathrm{mm} / \mathrm{s}$ was set during the cutting process with the diamond knife. The specimens were retrieved from the water and placed onto lacey carbon film on mesh copper grid.

\subsection{Laser interferometry}

Laser interferometry utilizing an optical wedge is a reliable tool for investigation of diffusion processes, with subsequent evaluation of the phase equilibrium of binary systems, including polymeric systems. ${ }^{39-41}$ Registration of the separate stages of the diffusion processes was used to calculate process kinetics. The interferometer consisted of the optical system, light source (a diode laser with $532 \mathrm{~nm}$ wavelength), camcorder and thermostated diffusion cell. Interferogram images were processed using traditional techniques. ${ }^{40}$ Kinetics of cross-linked PTMSP swelling was studied at $25^{\circ} \mathrm{C}$. A $60 \mu \mathrm{m}$ thick polymer film was placed between two glass plates, thus forming a diffusion cell. After that a solvent (chloroform, mixture of chloroform and trichloroethylene (1:1) and $0.5 \mathrm{wt} . \%$ PIM-1 solutions in both solvent systems) was added and interferograms were obtained and processed. 


\section{Results and discussion}

In our prior study on the use of PIM-1 for different applications, ${ }^{42-44}$ solutions of PIM-1 in chloroform were used to cast dense films. However, preliminary results on the fabrication of the selective layer using chloroform as a solvent revealed that all TFC membranes possessed average performance: the ideal $\mathrm{CO}_{2} / \mathrm{N}_{2}$ selectivity was in the range of 5-12, with a variety of $\mathrm{CO}_{2}$ permeances in the range 2100-10000 GPU. It was concluded that the fast evaporation of the highly volatile solvent, chloroform, might cause the formation of defects in the PIM-1 layer or non-uniform coating on top of cross-linked PTMSP. Later on, it was also reported in the literature ${ }^{45}$ that craters and defects with a size greater than the thickness of the top-layer might be frequently formed in a thin layer $(<500 \mathrm{~nm})$ of PIM-1, PIM-7 or PIM- 8 during dip coating on porous supports in the ultrafiltration range, based on PAN or cross-linked Ultem 1000 , of the polymer solution in chloroform. In another recent study, ${ }^{46}$ it was reported that the outer surfaces of the PIM layers were full of open pores and craters when the selective layer was deposited on top of a PDMS gutter layer by dip coating of hollow fibers with a PIM-1 solution in dichloromethane.

In this work, a PIM-1 solution in a mixture of chloroform and trichloroethylene (1:1) was proposed for the first time and successfully implemented for fabrication of thin film composite membranes based on the polymer of intrinsic microporosity. Chloroform and trichloroethylene have very close density, viscosity and solubility parameters, although there is a difference in the boiling points, at 61.2 and $87.2^{\circ} \mathrm{C}$, respectively (see Table 1). However, trichloroethylene is a "poor" solvent for PIM-1 (limited miscibility), only forming a one phase system at room temperature with a polymer content of $80 \%$ or higher (Fig. 1).

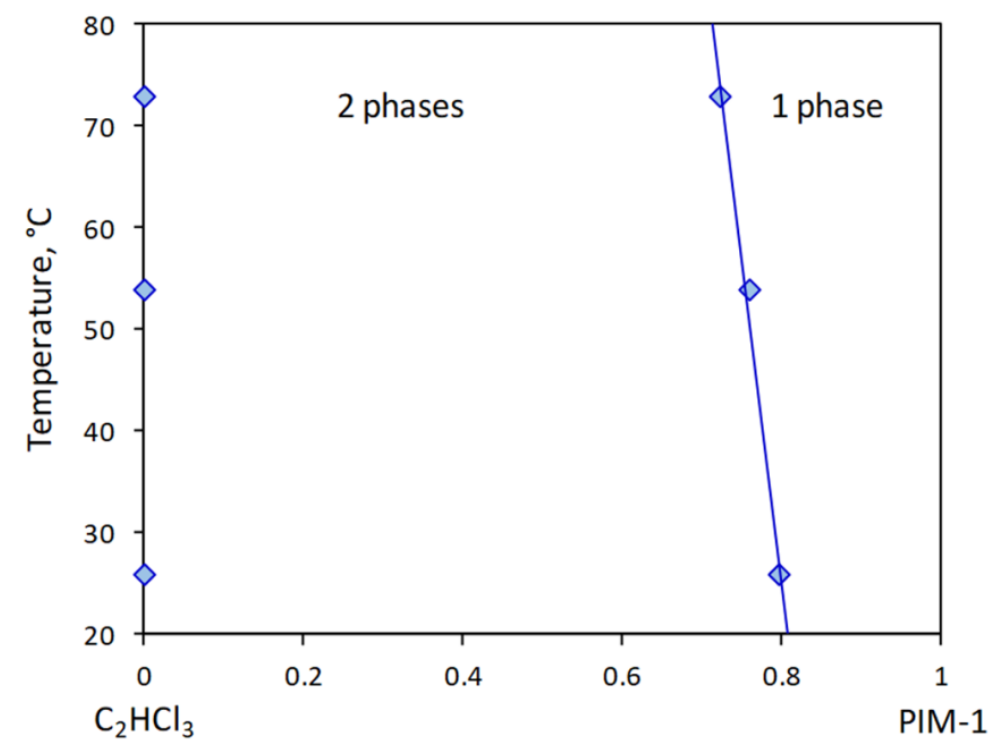

Fig. 1 Phase diagram for the system of PIM-1/trichloroethylene.

\subsection{Solvent evaporation from PIM-1 solutions}

Data on the solvent evaporation rate from PIM-1 solutions are presented in Fig. 2. As can be seen, the replacement of $50 \%$ of chloroform by trichloroethylene in the polymer solution allowed a noticeable reduction in the solvent evaporation rate. The most noticeable drop in evaporation rate was observed at the beginning, which could be attributed to the formation of a layer with a greater polymer concentration near the surface, due to fast evaporation of solvent from the subsurface region. The formation of this polymer-enriched surface layer slowed further evaporation of the solvent. In this first region, $15 \%$ of chloroform was evaporated with the highest evaporation rates of $1.2-1.5 \mathrm{mg} / \mathrm{cm}^{2} \mathrm{~s}$, while in the case of the solvent mixture only $4 \%$ of solvent, which is about four times lower than in the case of pure chloroform, was evaporated, with rates of about $0.8-1.0 \mathrm{mg} / \mathrm{cm}^{2} \mathrm{~s}$. Then, the evaporation of the major part of the solvent was accompanied by a slower drop in the evaporation rate. 


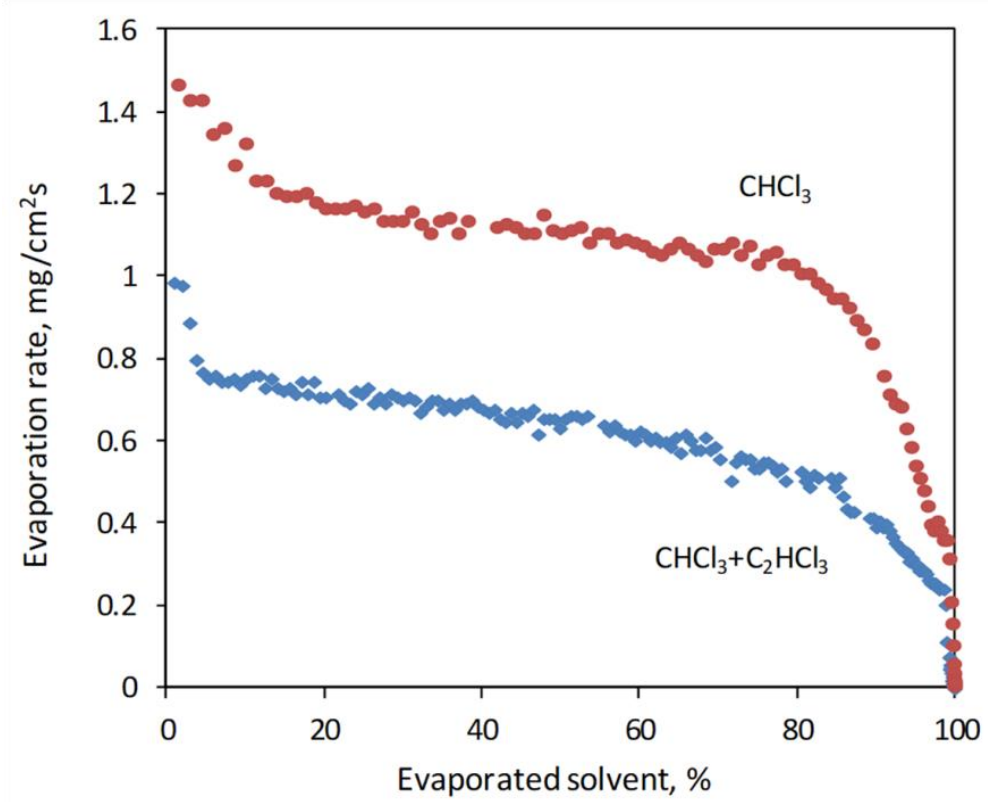

Fig. 2 Solvent evaporation rate from 0.5 wt.\% PIM-1 solution in chloroform and mixture of chloroform and trichloroethylene (1:1) as a function of evaporated solvent.

\subsection{Fabrication and structure of TFC membranes based on PIM-1}

The thin selective layer of PIM-1 was deposited by the "kiss-coating" technique (Fig. 3) on top of the high flux support recently developed for the fabrication of TFC membranes. ${ }^{33} \mathrm{~A}$ gutter layer made of cross-linked PTMSP allows application of the selective layer from a wide range of organic solvents. A solution of PIM-1 with a concentration of $0.5 \mathrm{wt} \%$ in a mixture of chloroform and trichloroethylene (1:1) was used as a casting solution.

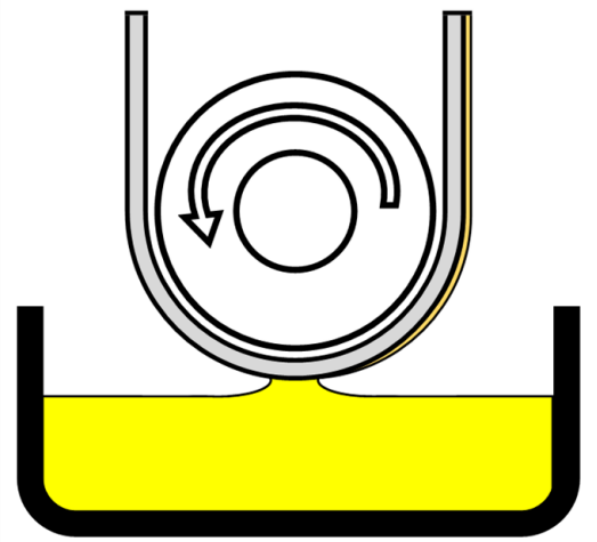

Fig. 3 Schematic representation of "kiss-coating" method of deposition of a thin top-layer on the support.

The cross-sections of TFC membranes, as visualized by scanning electron microscopy (SEM), show that the PIM-1 selective layer has a good adhesion to the cross-linked PTMSP gutter layer, and that both layers are well integrated on top of the microfiltration porous support (Fig. 4). Furthermore, the PIM-1 layer does not show visible defects or craters, as reported earlier in the literature, ${ }^{45,46}$ for either of the casting solutions, chloroform or a mixture of chloroform and trichloroethylene (1:1). It can be speculated that some of the solvent did not evaporate from the outer surface of PIM-1, but diffused into the PTMSP matrix, enabling the formation of a 
defect-free structure of the selective layer. With transmission electron microscopy (TEM) analysis it was possible to identify that the thin PIM-1 layer is placed on top of the gutter layer, as can be seen in Fig. 5, and that the selective layer is about 5-10 times thinner than the PTMSP layer. Both SEM and TEM analysis revealed no visible defects in either layer; however, it can be seen in Fig. 5 that the gutter layer has a non-uniform composition, which might be attributed to microheterogeneity of high molecular weight PTMSP and the presence of cross-linked hydrophilic polyethyleneimine in its hydrophobic matrix. EDS analysis of a cross-section was carried out for further evaluation of the structure of the top-layer (Fig. 6). EDS spectra reveal mainly $\mathrm{C}$ and $\mathrm{F}$ atoms in the microporous support, since MFFK- 1 has a top-layer made of tetrafluoroethylene/vinylidenefluoride copolymer (fluoroplastic F-42L) on polypropylene non-woven support. ${ }^{33}$ The amount of $\mathrm{F}$ atoms decreases down to zero in the gutter layer; however, $\mathrm{Si}$ atoms appear as one of the main components in this layer. It is important to point out that EDS confirms almost negligible intrusion of PTMSP into the microporous support, which, as described in Bazhenov et al. ${ }^{33}$ allowed the fabrication of a high-performance support $\left(\mathrm{CO}_{2}\right.$ permeance: $50-54 \mathrm{~m}^{3} /\left(\mathrm{m}^{2} \cdot \mathrm{h} \cdot\right.$ bar $\left.)\right)$ with a gas-selective gutter layer $\left(\alpha\left(\mathrm{CO}_{2} / \mathrm{N}_{2}\right)\right.$ : 3.6-3.7). When the outer selective layer is reached, no $\mathrm{Si}$ atoms can be observed in EDS spectra, which confirms that the thin top layer is only formed of PIM-1. After the selective layer, the counts of carbon decrease to some extent due to the slightly different composition of the epoxy resin used for sample preparation for TEM analysis. In addition, the signals of copper and carbon are expected to appear in all the spectra due to the TEM grid, which is made of these elements. It can be concluded that TFC membranes developed in this study have two separate layers, cross-linked PTMSP and PIM-1; however, some interpenetration of the layers at the interface might be expected based on EDS spectra obtained using a FEI Tecnai G2 T20 microscope (see Fig. 6). Therefore, further analysis of the interphase gutter layer/PIM layer was performed using a probe-side aberration corrector microscope (FEI Titan ChemiSTEM) which allows higher resolution and better sensitivity of the EDS detector. This microscope was operated in a STEM mode and elemental analysis was obtained by EELS. As can be seen in the elemental profiles of Fig. 7, the interphase between bulk PIM-1 and bulk x-PTMSP layers extended over $5 \mathrm{~nm}$.

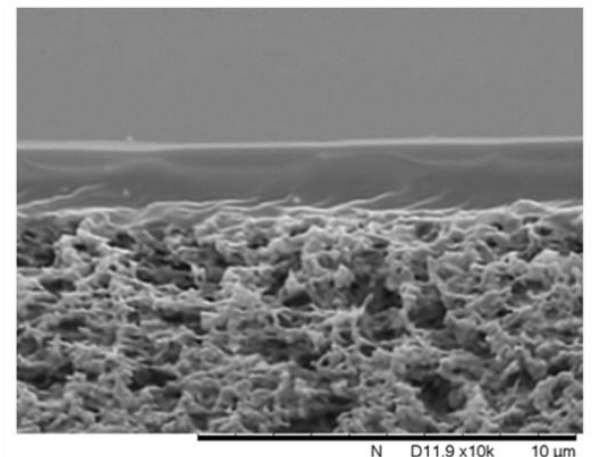

a

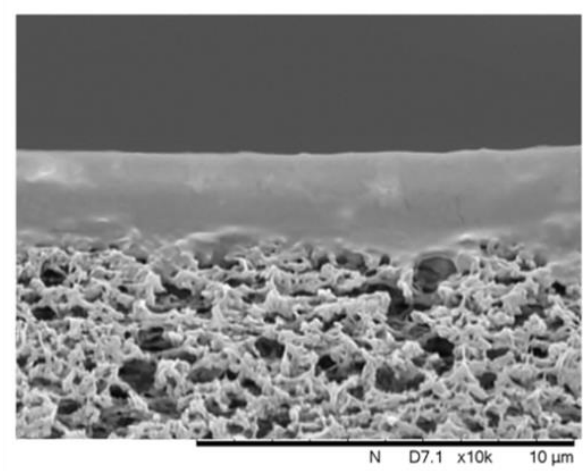

C

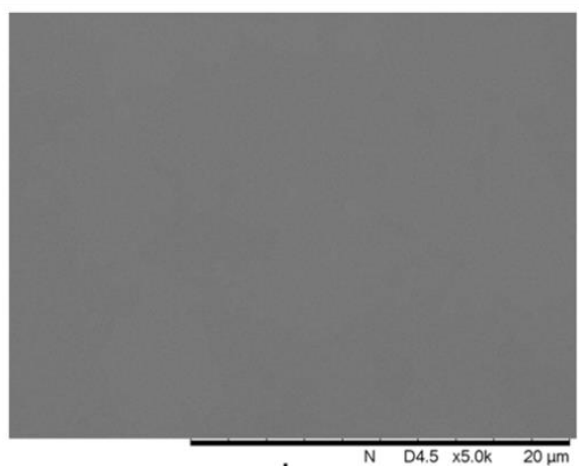

b

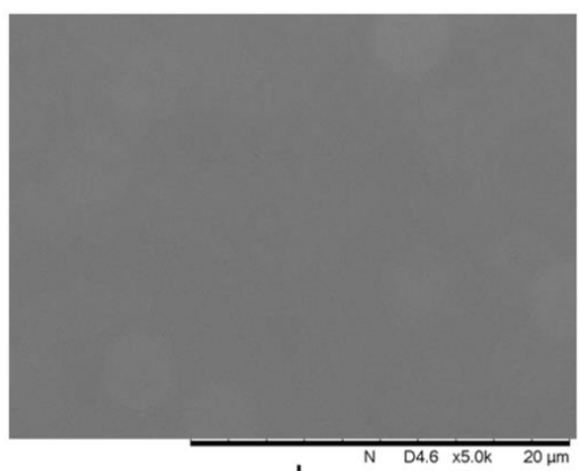

d

Fig. 4 Cross-section and surface SEM visualization of TFC membranes with PIM-1 selective layer on cross-linked PTMSP gutter layer: PIM-1 deposition from chloroform solution ( $a$ and $b$ ) and from mixture of chloroform and trichloroethylene (c and d). 


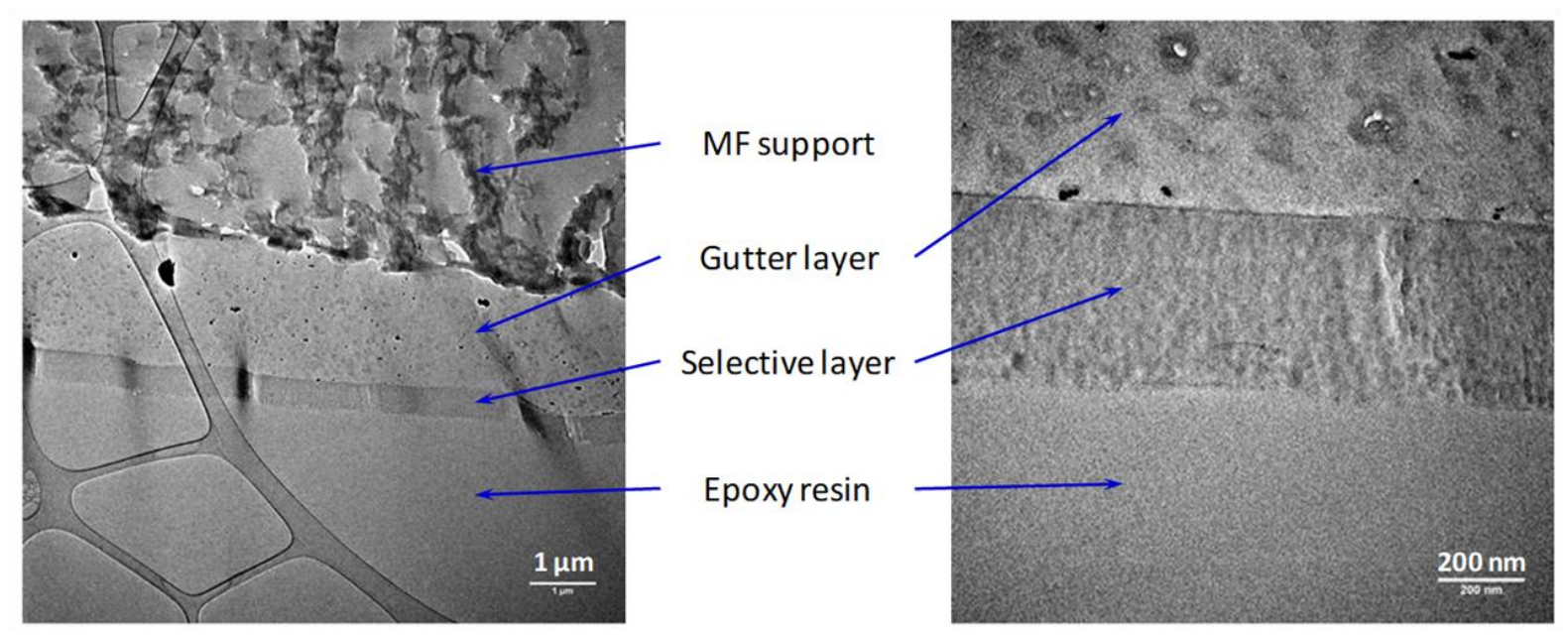

Fig. 5 TEM visualization of a cross-section of a TFC membrane.
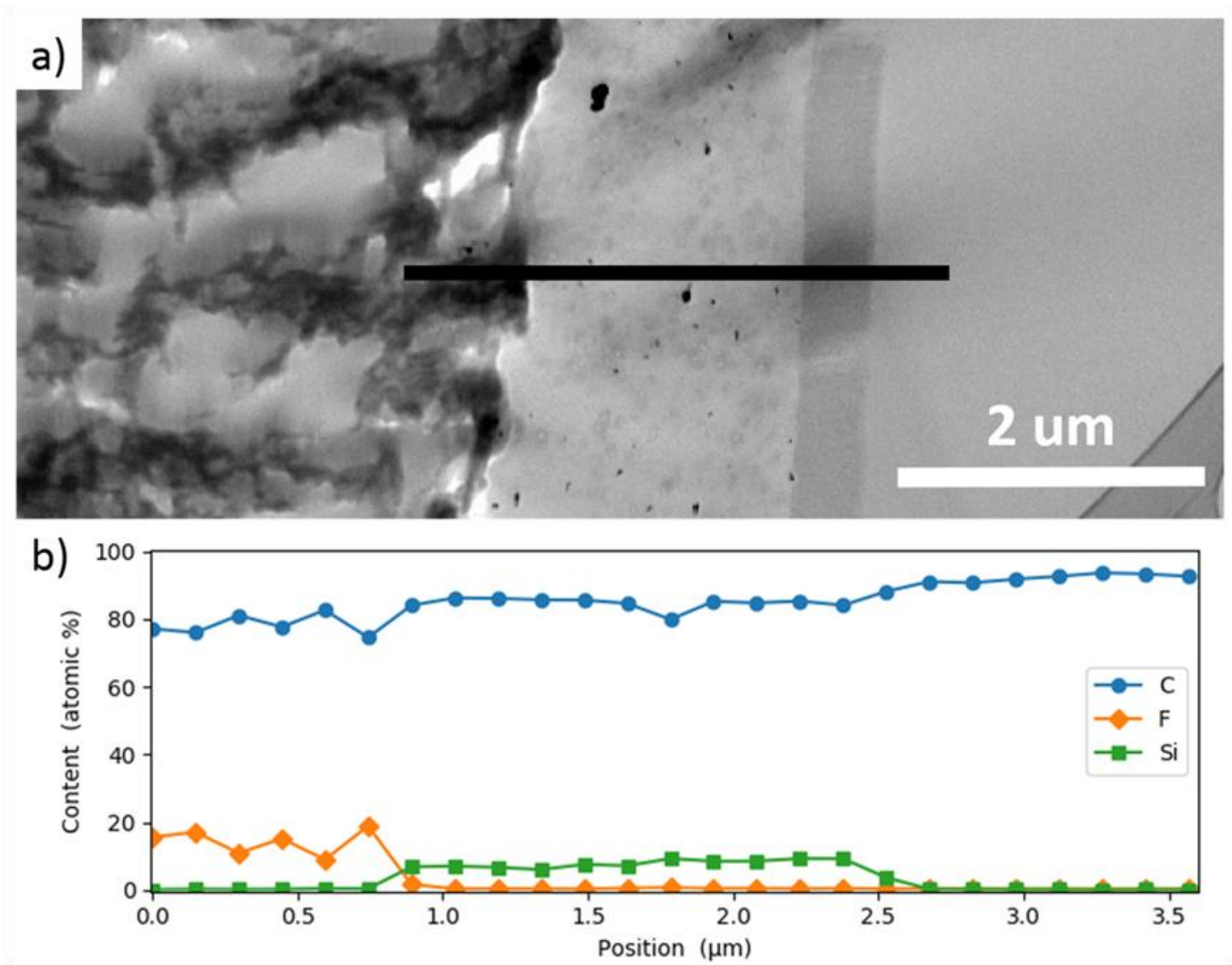

Fig. 6 a) STEM-bright field image of a cross-section of a TFC specimen. b) C, F and Si elemental STEM-EDS profile measured from area indicated by the black line in a). 

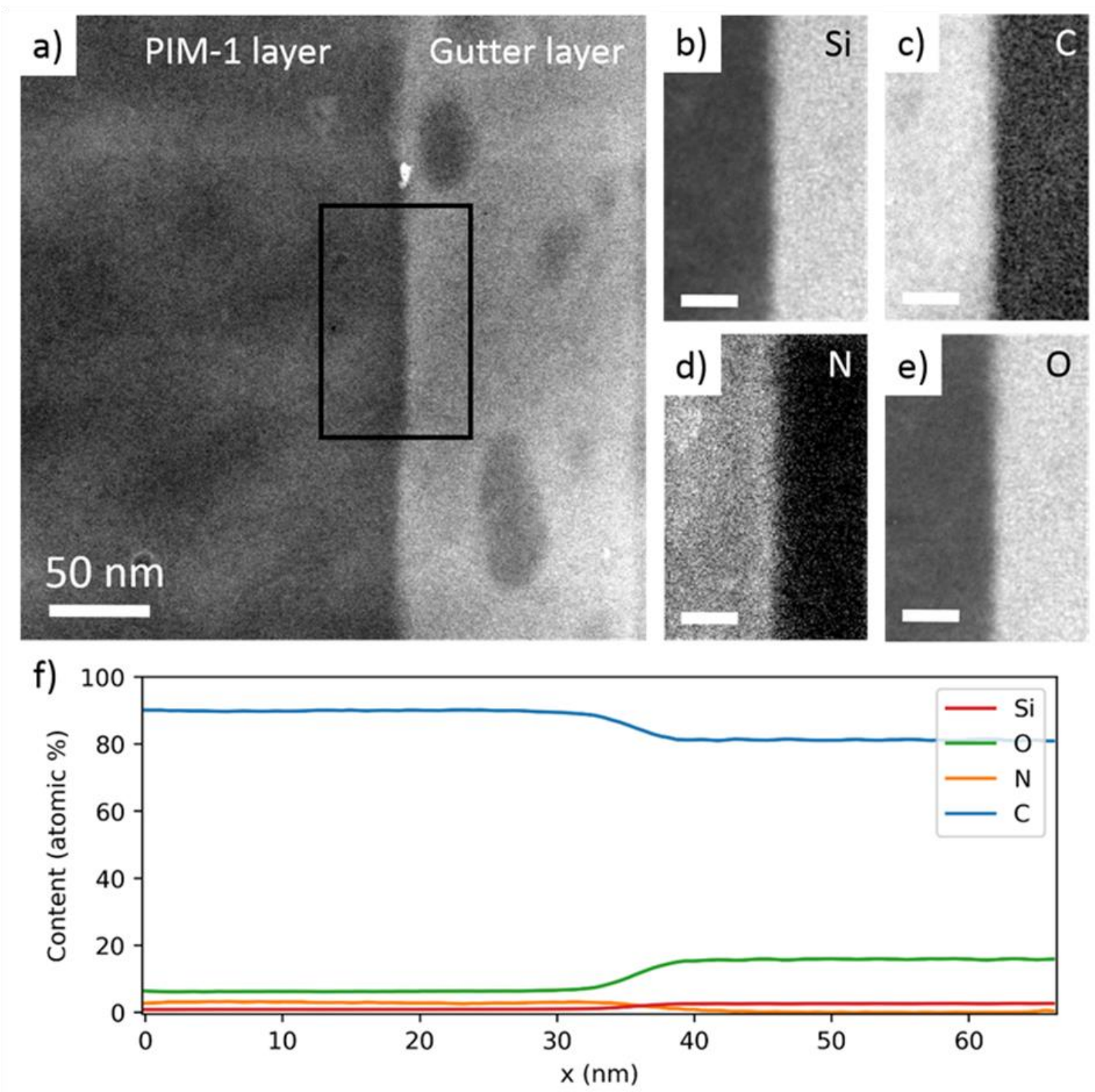

Fig. 7 a) STEM-HAADF images and b) Si, c) C, d) N and e) O elemental maps of the PIM-1/gutter layer interface obtained from EELS and acquired in the area marked by black rectangle. f) Elemental profiles averaged over the vertical direction of the elemental maps. The scale bar in b-e) is $20 \mathrm{~nm}$.

To estimate the thicknesses of the PIM-1 and x-PTMSP layers, five different areas were measured for each TFC membrane sample, and then five thickness values were measured in each area, correspondingly. Table 2 presents the average thickness values for PIM-1 and cross-linked PTMSP and their standard deviations. As can be seen, the thickness of the PIM-1 layer obtained varied within the range of $0.29-0.42 \mu \mathrm{m}$, even though the same casting solution and fixed conditions were used to fabricate all of the TFC membranes. Such differences in the resulting PIM-1 thickness might possibly be explained by some features of the "kiss-coating" method. In particular, this is not a classical dip coating method where the support is immersed into the casting solution, but the contact between the support and polymeric solution is maintained by the presence of liquid surface tension. Firstly, the support is brought into contact with the polymeric solution, then slightly lifted up and fixed above the surface of the liquid, while some contact with the solution is still maintained through the meniscus thanks to surface tension (see Fig. 3). There is typically an excess of the PIM-1 solution to ensure that the volume of solution consumed for fabrication of one TFC membrane sample would not lead to any noticeable change in the liquid level. However, some deviations in the setting of the distance between 
the support and the liquid surface might cause a change in the shape of the meniscus, and hence the contact area, which might affect the consumption of polymer solution. Regardless of this limitation, the "kiss-coating" method provides a number of important advantages, namely: (i) it is possible to use low viscosity solutions to obtain a uniform thickness of the top-layer, (ii) there is no contact of the backside of the support with the casting solution, which reduces the consumption of the polymer and does not block the pores of the support, (iii) there is a very short time and area of contact with the support, which might be important, for instance, when the top/gutter layer of the support material might interact with some components of the casting solution.

Table 2 TFC membranes based on PIM-1: thickness of selective (PIM-1) and gutter (x-PTMSP) layers, gas permeance and ideal selectivity.

\begin{tabular}{lccccc}
\hline \multirow{2}{*}{$\begin{array}{l}\text { TFC membrane } \\
\text { sample }\end{array}$} & \multicolumn{2}{c}{ Layer thickness, $\mu \mathrm{m}$} & \multicolumn{2}{c}{ Gas permeance, GPU } & \multirow{2}{*}{$\alpha\left(\mathrm{CO}_{2} / \mathrm{N}_{2}\right)$} \\
\cline { 2 - 4 } & $0.29 \pm 0.02$ & $2.31 \pm 0.63$ & 224 & $\mathrm{NO}_{2}$ & \\
\hline TFC\#1 & $0.32 \pm 0.01$ & $3.44 \pm 0.47$ & 80 & 8010 & 35.8 \\
TFC\#2 & $0.34 \pm 0.01$ & $2.07 \pm 0.28$ & 127 & 2930 & 36.6 \\
TFC\#3 & $0.21 \pm 0.01$ & $1.33 \pm 0.05$ & 75 & 4930 & 38.8 \\
TFC\#4 & $0.26 \pm 0.01$ & $2.25 \pm 0.32$ & 52 & 3260 & 43.5 \\
TFC\#5 & $0.42 \pm 0.01$ & $2.07 \pm 0.58$ & 54 & 2720 & 52.3 \\
TFC\#6 & & x-PTMSP & 3010 & 55.7
\end{tabular}

\subsection{Gas transport properties of TFC membranes based on PIM-1}

Dense films of PIM-1 with a thickness of $20 \mu \mathrm{m}$ and of cross-linked PTMSP (x-PTMSP) showed $\mathrm{CO}_{2} / \mathrm{N}_{2}$ selectivities of 18.5 (this study) and 3.7, ${ }^{33}$ respectively. As can be seen from Table 2, all TFC membrane samples demonstrated a strong synergistic enhancement of $\mathrm{CO}_{2} / \mathrm{N}_{2}$ selectivity $(\alpha=35.8-55.7)$ compared to PIM-1 $(\alpha=18.5)$ and x-PTMSP $(\alpha=3.7)$. It should be noted that the $\mathrm{CO}_{2} / \mathrm{N}_{2}$ selectivity reported in the literature for PIM-1 varies over a wide range, from $11,{ }^{47} 15^{48,49}$ up to $18-25^{50-52}$, which is subject to the sample's pre-history, to experimental conditions and to effects of moisture. Therefore, we compare the gas permeability data for TFC membranes with dense PIM-1 membranes prepared from the same batch of PIM-1 under the same conditions; the gas permeation measurements were carried out using the same set-up.

It is possible that partial interpenetration of the two polymers could occur during the TFC membrane preparation, resulting in the formation of a hybrid polymeric material, which could possess different gas transport properties. Regretfully, it was not possible to obtain defect-free, uniform, dense films from the mixture of chloroform/trichloroethylene, since PIM-1 possesses very limited solubility in trichloroethylene (see Fig. 1). During the evaporation, microphase separation began to occur in the polymer solution, causing the formation of cloudy regions. When $79-80 \%$ of the solvent mixture had evaporated, simultaneous phase separation took place causing polymer precipitation.

Bearing this in mind, dense PTMSP/PIM-1 blend films with a thickness of 25-30 $\mu \mathrm{m}$ were prepared from a common solution in chloroform. There is a classical trade-off between gas permeability and selectivity for all PTMSP/PIM-1 blends, as can be seen in Fig. 8. To evaluate the performance of PTMSP/PIM-1 blends in the form of a thin selective layer, a TFC composite membrane with a top-layer made of a PTMSP/PIM-1 blend (9:1) was cast on top of the MFFK-1/x-PTMSP support. The resulting TFC membrane demonstrated moderate gas transport properties $-\mathrm{CO}_{2}$ permeance of $9600 \mathrm{GPU}$ and ideal selectivity for the $\mathrm{CO}_{2} / \mathrm{N}_{2}$ pair of 6.1 - which was lower than the value observed for a dense film with the same PIM-1 content in PTMSP of $10 \mathrm{wt} . \%(\alpha=7.8)$. 
It should be noted that the PIM-1 polymer possesses a certain molecular weight distribution $\left(M_{\mathrm{w}}=270000 \mathrm{~g} / \mathrm{mol} ; M_{\mathrm{w}} / M_{\mathrm{n}}=2.8\right)$ and contains a fraction of oligomers. It is possible that PIM-1 oligomer molecules with higher mobility might diffuse into the PTMSP matrix, changing its porous structure and, therefore, gas selectivity. However, blends of PTMSP with cyclic $\left(M_{\mathrm{w}}=8100 \mathrm{~g} / \mathrm{mol} ; M_{\mathrm{w}} / M_{\mathrm{n}}=1.30\right)$ or linear $\left(M_{\mathrm{w}}=12300 \mathrm{~g} / \mathrm{mol} ; M_{\mathrm{w}} / M_{\mathrm{n}}=1.62\right)$ PIM-1 oligomers did not reveal any noticeable difference compared with the performance of polymer blends (see Table 3). Consequently, it can be concluded that the diffusion of polymer or oligomer chains of PIM-1 into the PTMSP matrix cannot adequately explain the superior selectivity of the TFC membranes, since the blends of PTMSP with PIM-1 polymer or oligomer did not show any noticeable increase in gas selectivity.

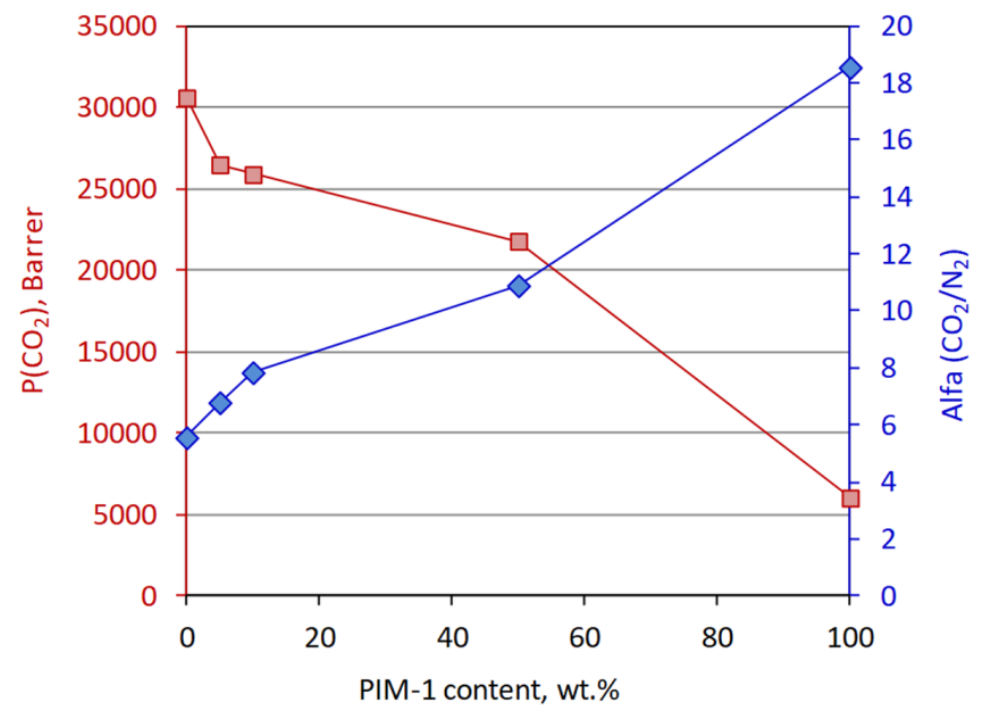

Fig. 8 PTMSP/PIM-1 blends (25-30 $\mu$ m thickness): $\mathrm{CO}_{2}$ permeability coefficient and ideal selectivity of $\mathrm{CO}_{2} / \mathrm{N}_{2}$ as a function of PIM-1 content.

Table 3 Performance of blends of PTMSP with PIM-1 polymer or oligomers (film thickness of 25-27 $\mu$ m).

\begin{tabular}{lccc}
\hline \multicolumn{1}{c}{ Additive } & PIM-1 content in PTMSP, wt.\% & $\mathrm{P}\left(\mathrm{CO}_{2}\right)$, Barrer & $\alpha\left(\mathrm{CO}_{2} / \mathrm{N}_{2}\right)$ \\
\hline Polymer PIM-1 & 0.5 & 33400 & 5.9 \\
Cyclic PIM-1 oligomer & & 36300 & 5.7 \\
Linear PIM-1 oligomer & & 37000 & 5.6 \\
\hline Polymer PIM-1 & 1.0 & 40200 & 5.1 \\
Cyclic PIM-1 oligomer & & 36900 & 5.5 \\
Linear PIM-1 oligomer & & 37000 & 5.5
\end{tabular}

\subsection{Laser interferometry study}

To better understand the interactions between the casting solution of PIM-1 and the gutter xPTMSP layer, laser interferometry was used. Laser interferometry is a powerful technique for studying the phase transformations and diffusion processes in multi-component systems ${ }^{52,53}$ In this method, two phases, such as liquid-liquid or liquid-solid, are brought into contact in the gap between two glass plates at a small angle (wedge). Monochromatic light goes through the first glass plate and the studied system of two phases, then reflects back from the surface of the second glass plate, which is covered typically by a thin metal layer (e.g. gold). The incident and reflected waves interact to form an interference pattern. If the two phases have a difference in their refractive index, then the phase transformations over time can be monitored 
by the change of the interference images. The mutual diffusion of the liquid phase into the polymer matrix can be described by the following equation: ${ }^{40,54}$

$$
D=\frac{x^{2}}{6 t}
$$

where $D$ is the diffusion coefficient, $t$ is the time from the beginning of the diffusion and $x$ is the coordinate along the mass transfer axis.

In this study, dense cross-linked PTMSP films of about $60 \mu \mathrm{m}$ were placed into contact with chloroform, with a mixture of chloroform and trichloroethylene (1:1) and with 0.5 wt.\% PIM1 solutions in both solvent systems. Figs. 9 and 10 represent interferograms recorded at the beginning $(0 \mathrm{sec})$ and after 30,90 and $270 \mathrm{sec}$ of contact of $\mathrm{x}$-PTMSP film with solvents and PIM-1 solutions, respectively. It can be seen that the swelling of x-PTMSP was accompanied by the formation of a diffusive region possessing a variable refractive index from the initial $\mathrm{x}$ PTMSP to liquid phases.
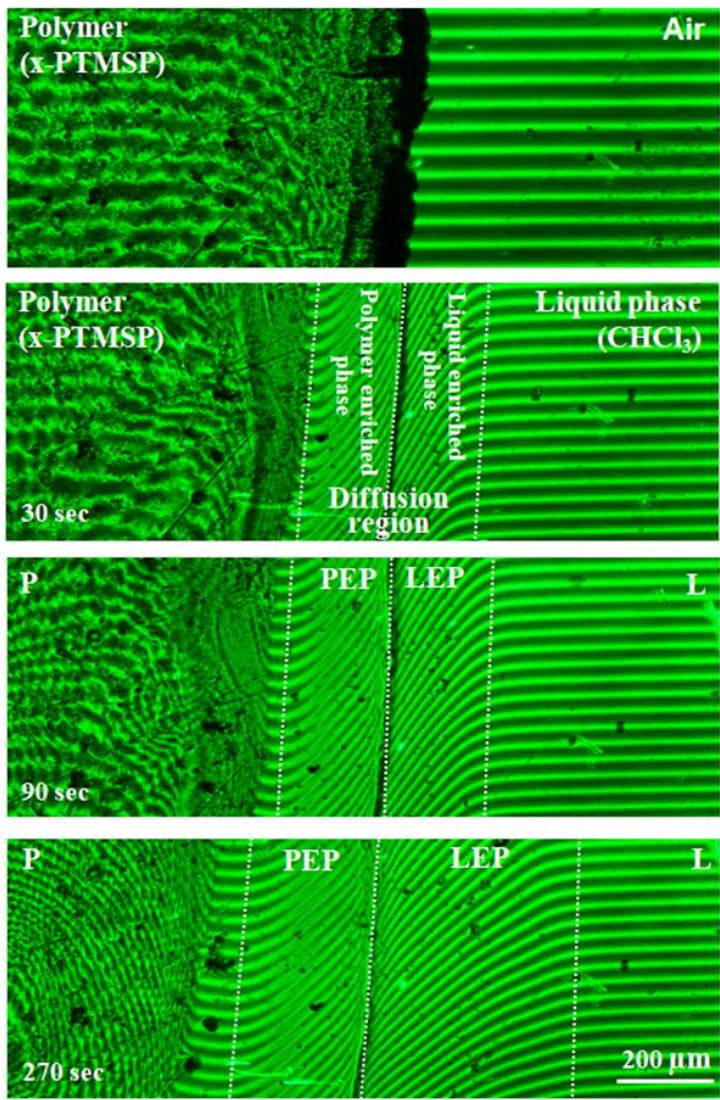
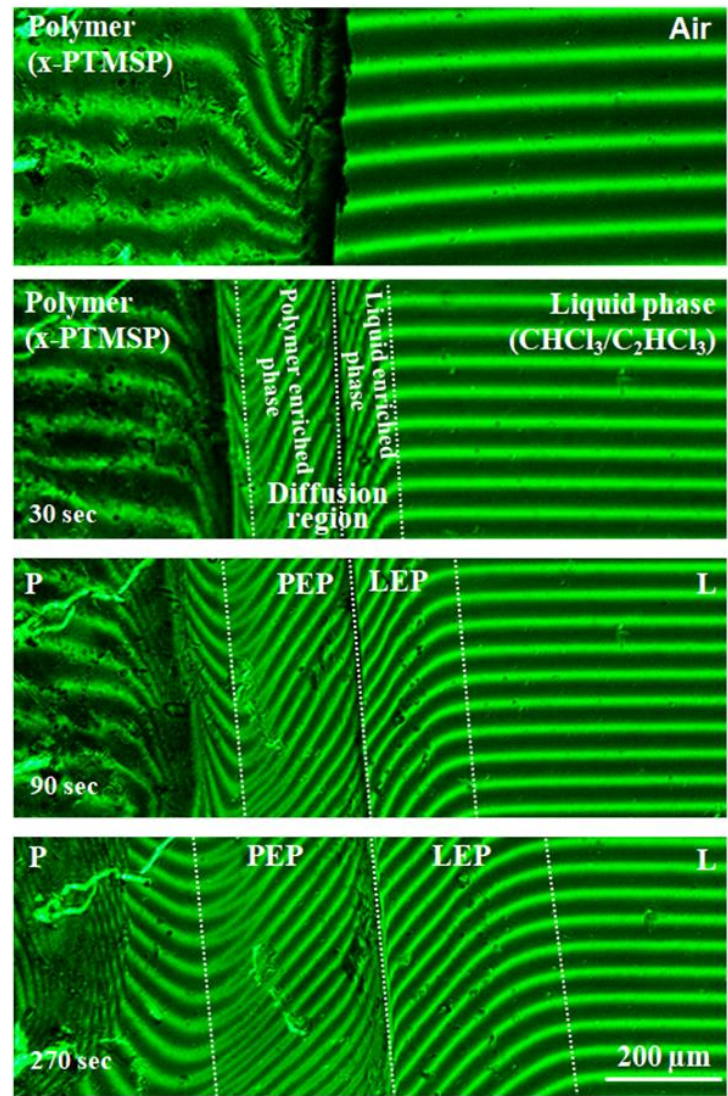

Fig. 9 Interferograms of cross-linked PTMSP (P) at room temperature 0, 30, 90 and $270 \mathrm{sec}$ after the contact with the liquid phase (L): a) chloroform (left), and b) chloroform/trichloroethylene (right). 

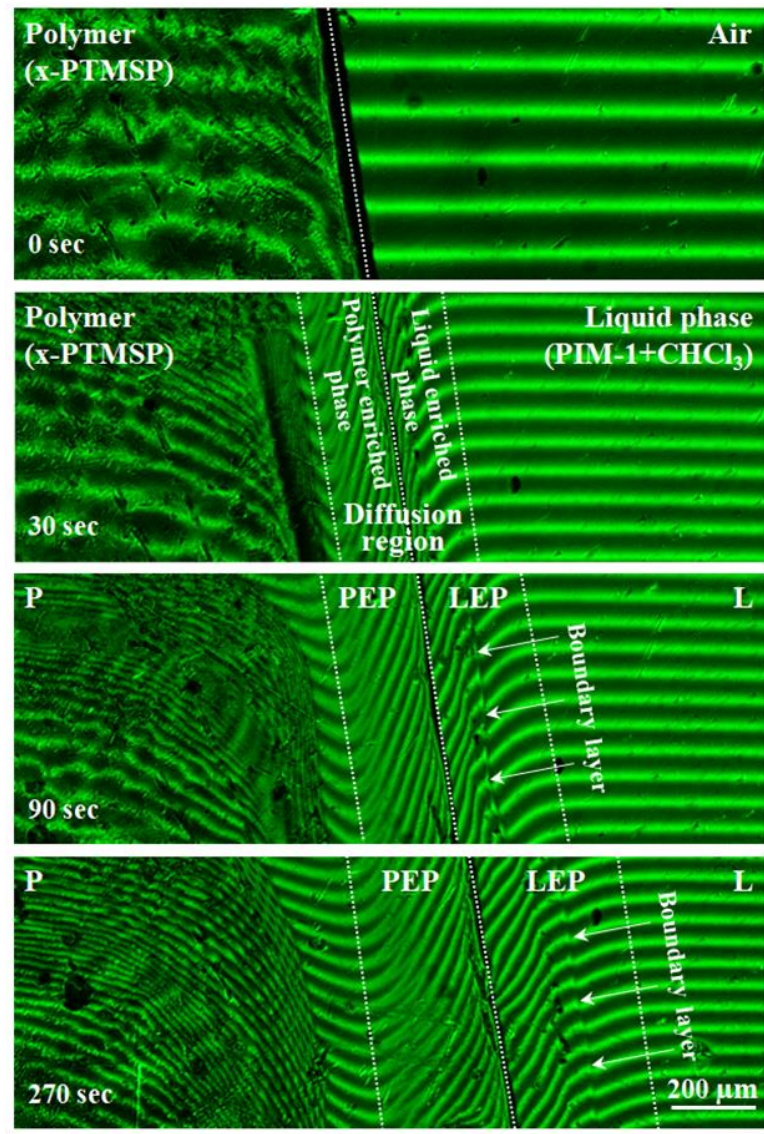
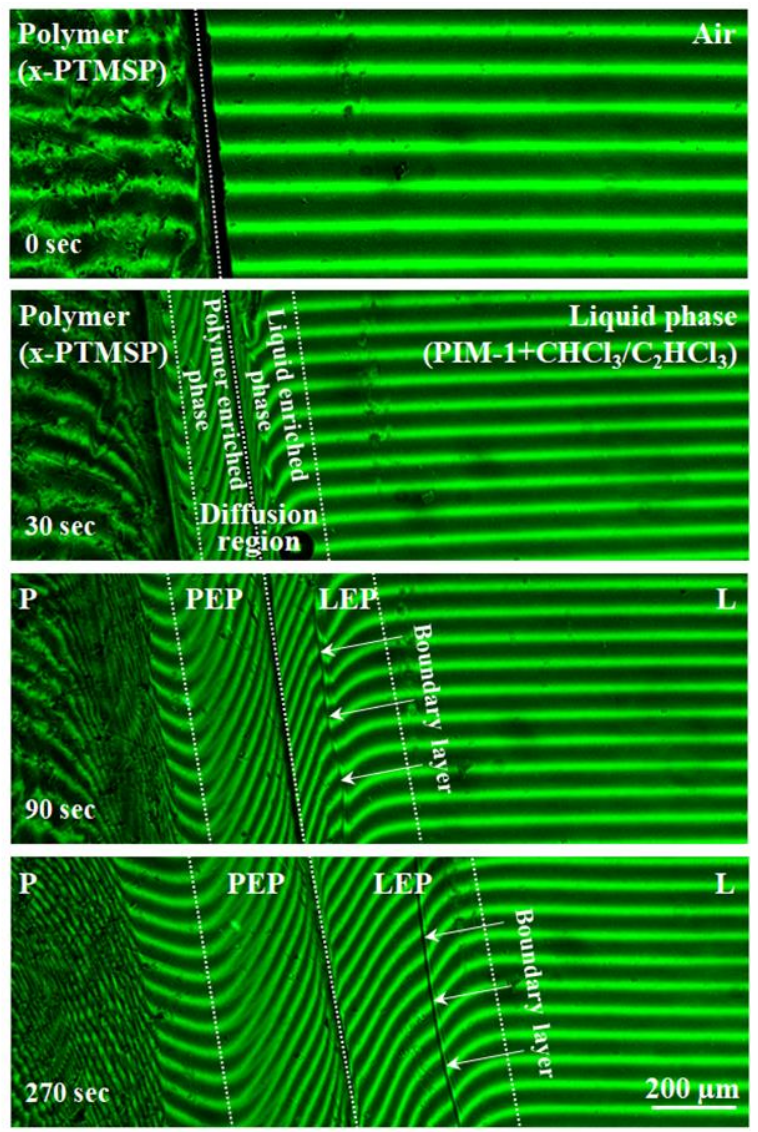

Fig. 10 Interferograms of cross-linked PTMSP $(\mathrm{P})$ at room temperature 0, 30, 90 and $270 \mathrm{sec}$ after the contact with the liquid phase (L) consisting of: a) $0.5 \mathrm{wt} . \%$ PIM-1 solution in chloroform (left), and b) $0.5 \mathrm{wt}$ \% PIM-1 solution in chloroform/trichloroethylene (right).

The diffusion region was visually divided into two areas, polymer enriched phase (PEP phase), which was in contact with the x-PTMSP, and liquid enriched phase (LEP phase), which was in contact with the surrounding liquid. With the course of time, the thicknesses of the diffusion region and of each layer increased as expected. Fig. 11 demonstrates the PTMSP concentration profiles for the times of 90 and $270 \mathrm{sec}$ after the contact of the corresponding solution with $\mathrm{x}$-PTMSP, calculated from the interferograms ${ }^{55,56}$. It can be seen that the PTMSP fraction in the PEP region drops from 1 down to 0.44-0.45 regardless of the solvent system and observation time. When PIM-1 solution contacted x-PTMSP film, the formation of an additional boundary layer within the liquid enriched phase was observed (see the interferograms after $30 \mathrm{sec}$ in Fig. 10). It is important to note that the boundary layer was thin and dense in the case of PIM-1 solution in chloroform/trichloroethylene, compared to the broader and more diffuse boundary layer seen in the case of PIM-1 solution in chloroform (see the interferograms at $270 \mathrm{sec}$ in Fig. 10). It is feasible that the sharp boundary layer observed with the mixed solvent is associated with precipitation of a thin PIM-1-rich film. It should be noted that the thickness of the diffusion region (PEP+LEP) for both solvent systems was nearly the same at $460-480 \mu \mathrm{m}$ after $90 \mathrm{sec}$ of contact (see Fig. 11). However, for PIM-1 solutions, lower penetration into the $\mathrm{x}$-PTMSP was observed in the case of chloroform/trichloroethylene (PEP region: $210 \mu \mathrm{m}$ ) in contrast to chloroform (PEP region: $250 \mu \mathrm{m}$ ), and the difference in the penetration depth for the two solvent systems further increased with increase in time, 320 and $430 \mu \mathrm{m}$, correspondingly. Such difference in the behavior can be attributed to additional mass-transfer resistance due to the formation of a boundary layer in the case of chloroform/trichloroethylene. 

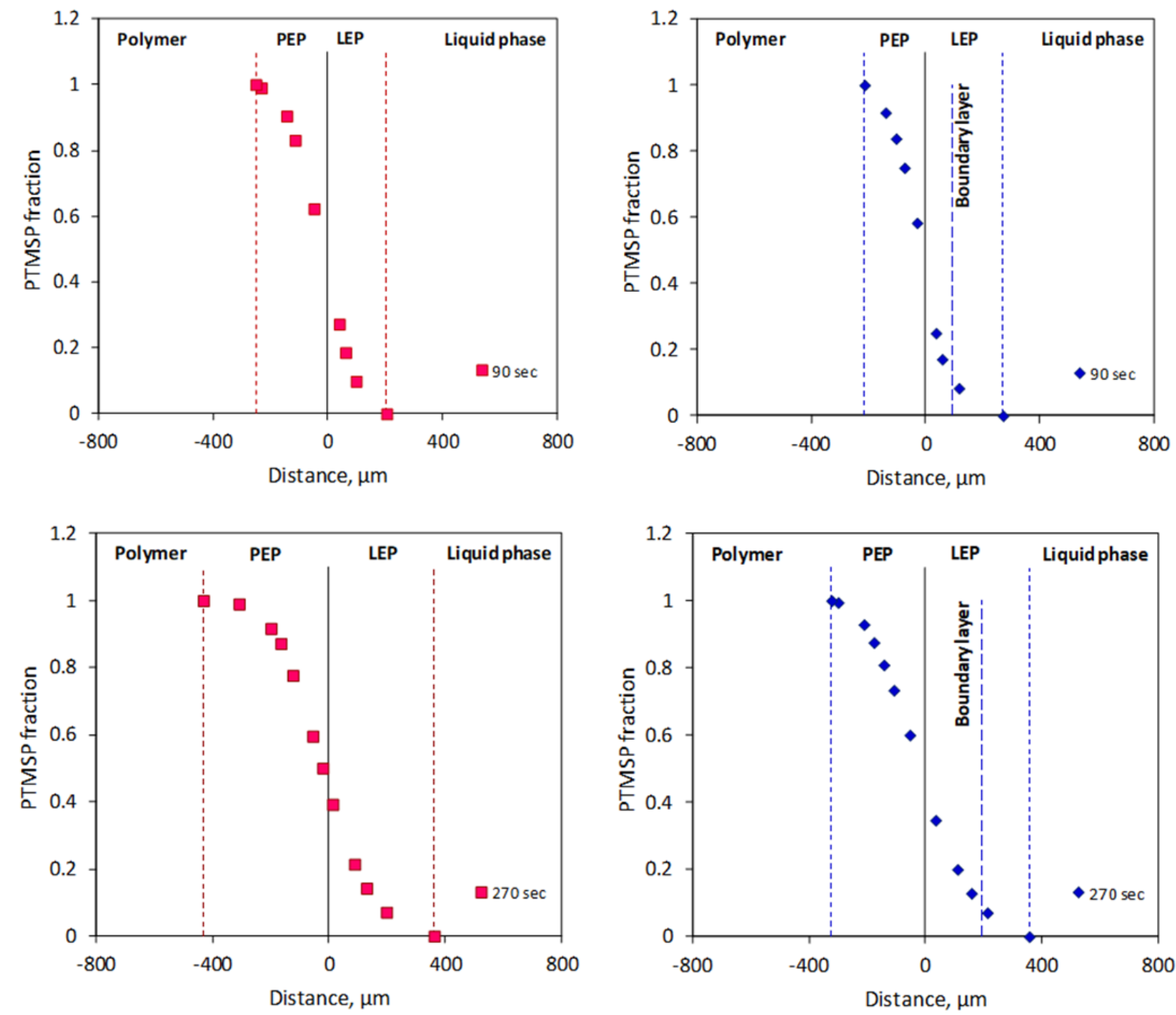

Fig. 11 PTMSP concentration profile after 90 and $270 \mathrm{sec}$ after the contact with the liquid phase (L) consisting of: a) 0.5 wt.\% PIM-1 solution in chloroform (left), and b) 0.5 wt.\% PIM-1 solution in chloroform/trichloroethylene (right). The vertical line represents the original polymer-liquid interface (distance zero), the vertical dashed lines represent the distance where PTMSP concentration becomes 0 or 1 , respectively. The additional vertical dashed line visualizes the position of the "boundary layer".

The dashed lines between the PEP and LEP regions in Figs. 9 and 10 mark the original polymer-liquid interface at the beginning of the experiment (time: $0 \mathrm{sec}$ ). Fig. 12 shows the position of the front of each zone in time from the initial polymer-liquid interface. The diffusion coefficients for the frontal zones were estimated using equation (1) and the corresponding slopes from Fig. 12. The calculated diffusion coefficients of each zone, such as polymer enriched phase, liquid enriched phases and boundary layer, are listed in Table 4. To summarize our observations (see Figs. 9 and 10, and Table 4):

1. A surface layer of cross-linked PTMSP started to swell once the polymer film was brought into contact with solvent or PIM-1 solution.

2. The formation of an additional boundary layer was visualized for PIM-1 solutions. This layer can be attributed to a PIM-1 enriched phase. There is a noticeable difference in the structure of the boundary layer between chloroform and the mixed solvent, being much thinner and denser in the case of PIM-1 solution in chloroform/trichloroethylene.

3 . The presence of trichloroethylene in the liquid phase accelerated the swelling of crosslinked PTMSP; the diffusion coefficient of the polymer enriched phase increased by a factor of 1.3 in going from chloroform to the chloroform/trichloroethylene mixture. 
4. The presence of PIM-1 polymer in the liquid phase hindered the further swelling of cross-linked PTMSP. The diffusion coefficients of zones of the polymer enriched phase dropped by a factor of 1.5 for chloroform, and 1.7 for chloroform/trichloroethylene. This could be related to the formation of the PIM-1 enriched boundary layer. At the same time, completely opposite behavior of the chloroform and chloroform/trichloroethylene systems was discovered. As can be seen from Table 4, the diffusion coefficient of zones of the liquid enriched phase increased by a factor of 1.5 in going from the mixture of solvents to the PIM-1 solution in chloroform/trichloroethylene mixture. It cannot be too highly stressed that this gives the highest value of the diffusion coefficient. Thus, the thin boundary layer is stable and mobile in the course of the interaction of PIM-1 solution with x-PTMSP. It is expected that this observation is also valid for the process of TFC membrane preparation by coating PIM-1 solution in chloroform/trichloroethylene mixture (1:1) on top of a x-PTMSP support.
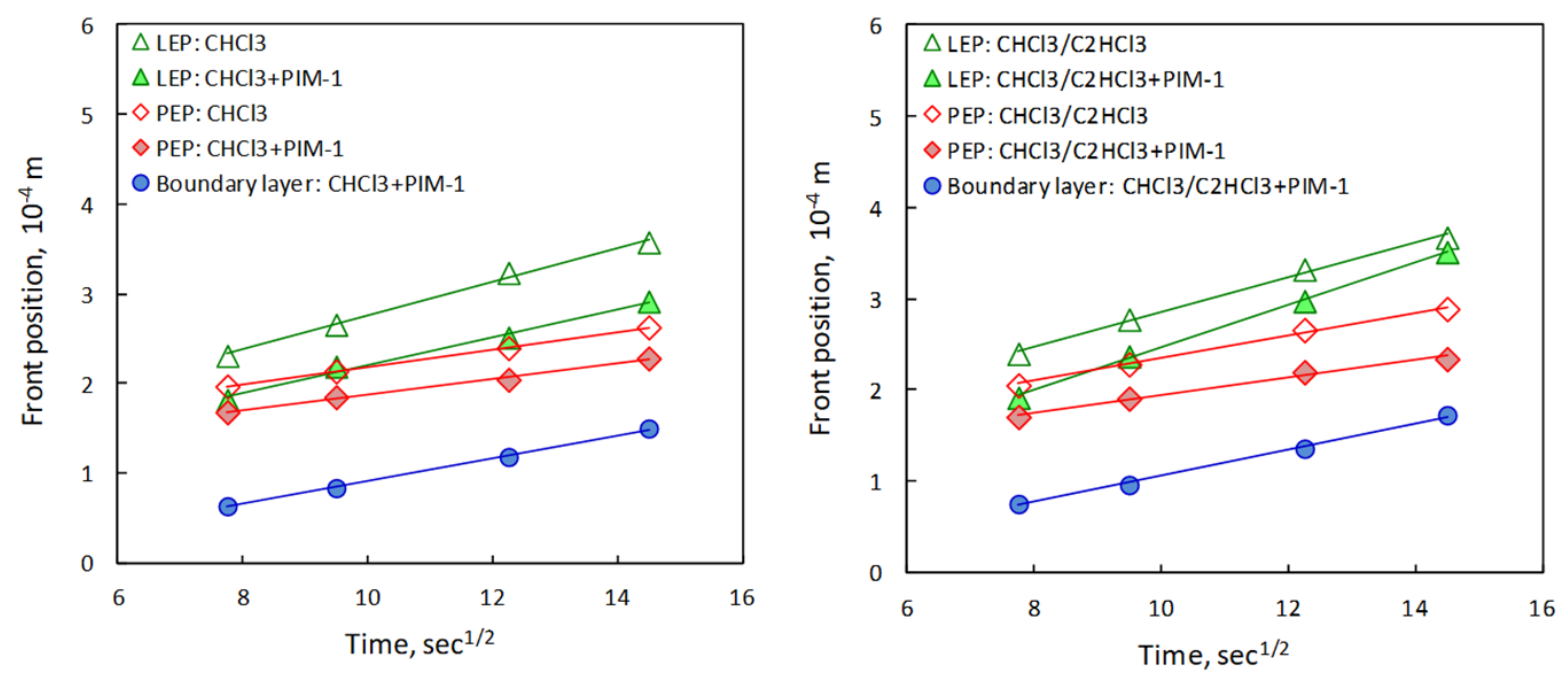

Fig. 12 The position of the front of each region in time (LEP - liquid enriched phase, PEL - polymer enriched phase). Left: $\mathrm{CHCl} 3$ - chloroform, $\mathrm{CHCl} 3+\mathrm{PIM}-1$ - 0.5 wt.\% PIM-1 solution in chloroform. Right: $\mathrm{CHCl} / \mathrm{C} 2 \mathrm{HCl} 3$ - chloroform/trichloroethylene, $\mathrm{CHCl} 3 / \mathrm{C} 2 \mathrm{HCl} 3+\mathrm{PIM}-1$ - 0.5 wt.\% PIM-1 solution in chloroform/trichloroethylene.

Table 4 Diffusion coefficients of polymer enriched and liquid enriched zones for swelling of cross-linked PTMSP and formation of PIM-1 diffusive layer.

\begin{tabular}{lccc}
\hline \multirow{2}{*}{\begin{tabular}{l} 
Liquid phase \\
\cline { 2 - 4 }
\end{tabular}} & $\begin{array}{c}\text { Diffusion coefficient } D, 10^{-11} \mathrm{~m}^{2} / \mathrm{s} \\
\text { enriched } \\
\text { phase }\end{array}$ & $\begin{array}{c}\text { Liquid } \\
\text { enriched } \\
\text { phase }\end{array}$ & $\begin{array}{c}\text { PIM-1- } \\
\text { enriched } \\
\text { boundary } \\
\text { layer }\end{array}$ \\
\hline Chloroform & 1.8 & 3.1 & $\mathrm{n} / \mathrm{a}$ \\
0.5 wt.\% PIM-1 in chloroform & 1.2 & 2.4 & 3.0 \\
Chloroform/trichloroethylene & 2.4 & 3.0 & $\mathrm{n} / \mathrm{a}$ \\
$\begin{array}{l}\text { 0.5 wt.\% PIM-1 in } \\
\text { chloroform/trichloroethylene }\end{array}$ & 1.4 & 4.4 & 3.4 \\
\end{tabular}

An analysis of the literature revealed that it was possible to obtain TFC membranes with similar performance in terms of $\mathrm{CO}_{2} / \mathrm{N}_{2}$ selectivity and $\mathrm{CO}_{2}$ permeance only by introduction of PEG-functionalized carbon nanotubes (CNT) in the PIM-1 thin layer (see data from ${ }^{57}$ on 
Fig. 13). In this work, we managed to engineer TFC membranes with high $\mathrm{CO}_{2}$ permeance and superior $\mathrm{CO}_{2} / \mathrm{N}_{2}$ selectivity due to the strong synergistic effect. Fig. 14 presents a schematic structure of the TFC membranes developed. Preparation of TFC membranes using good PIM1 solvents like chloroform failed to reach a goal of enhanced $\mathrm{CO}_{2} / \mathrm{N}_{2}$ selectivity. However, the PIM-1 solution in a mixture of chloroform and trichloroethylene (1:1) was successfully implemented for fabrication of both high flux and high selectivity TFC membranes using recently developed supports with a gutter layer based on cross-linked PTMSP. According to the results obtained by the laser interferometry method, the pronounced difference between these two systems is a very thin PIM-1/x-PTMSP boundary layer for PIM-1 solution in chloroform/trichloroethylene mixture, in contrast to a broad and diffuse one in the case of PIM-1 solution in chloroform. Therefore, the synergistic enhancement of gas selectivity in the developed TFC membranes most likely occurs due to the creation of a very thin boundary layer between PIM-1 and the cross-linked PTMSP gutter layer.

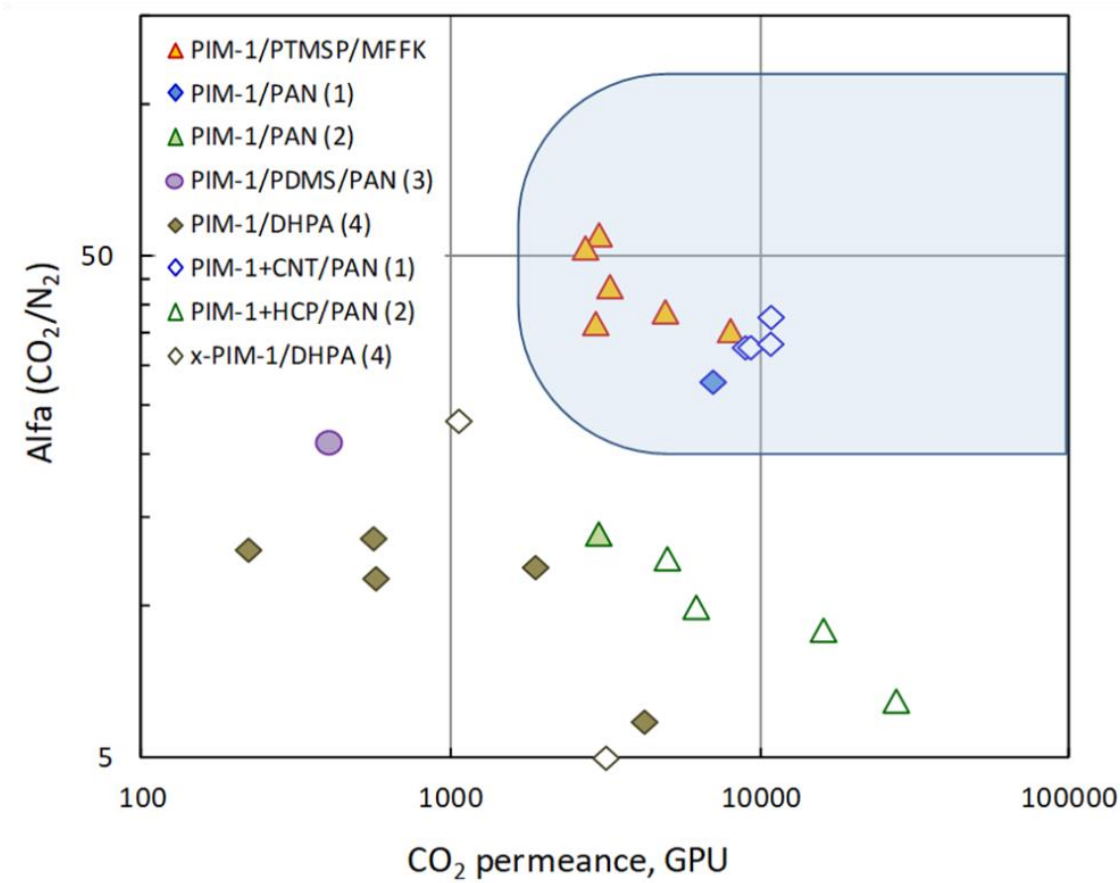

Fig. 13 TFC membranes based on PIM-1 (closed symbols - pristine PIM-1; open symbols - mixed matrix membranes based on PIM-1): Selectivity versus $\mathrm{CO}_{2}$ permeance. Shaded area - optimal membrane properties for post-combustion $\mathrm{CO}_{2}$ capture suggested $\mathrm{in}^{30}$. Literature data: (1), ${ }^{55}(2),{ }^{56}$ $(3),{ }^{46}(4) .{ }^{57}$

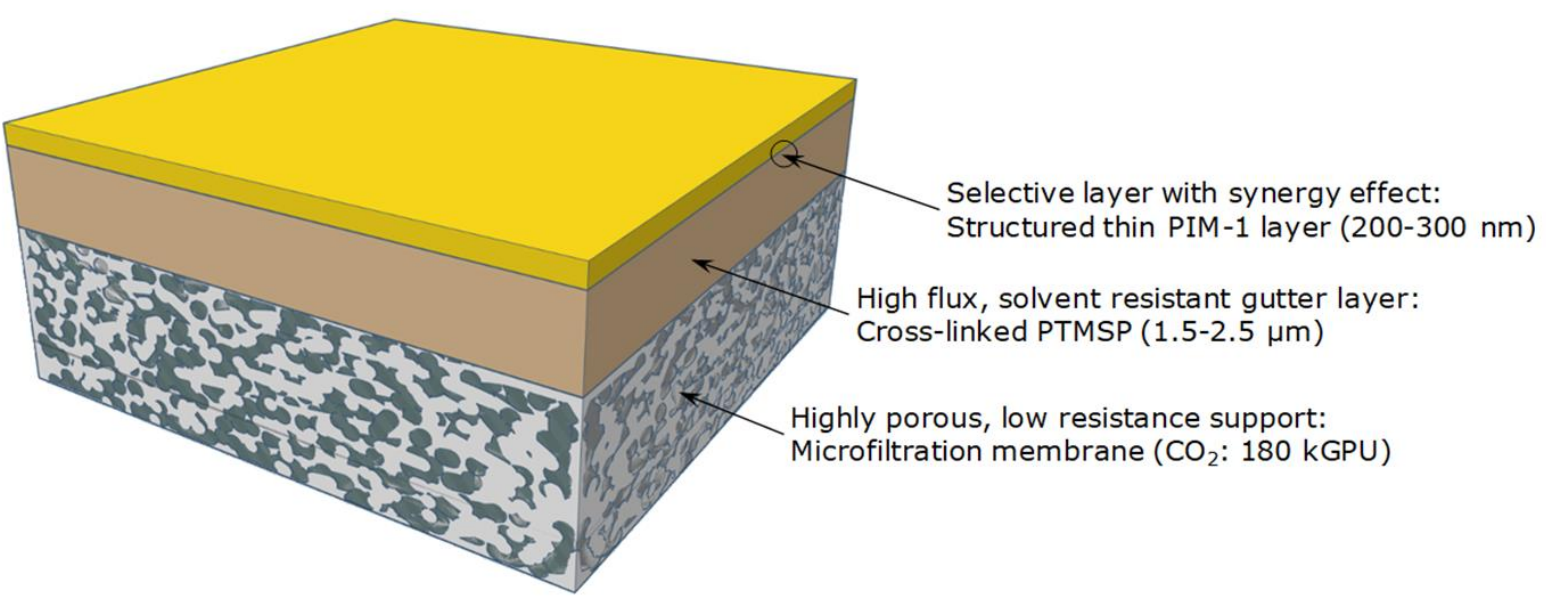

Fig. 14 Membrane engineering: the concept of the TFC membrane with superior selectivity. 
As can be seen in Fig. 13, the as-cast TFC membranes met the optimal membrane properties for post-combustion $\mathrm{CO}_{2}$ capture suggested by Merkel et al. ${ }^{30}$ In a recent publication ${ }^{46}$, multiple-layer hollow fibers with a $\mathrm{CO}_{2}$ permeance of $402.6 \mathrm{GPU}$ and $\mathrm{CO}_{2} / \mathrm{N}_{2}$ selectivity of 21.3 were prepared with a selective PIM-1 layer of $\sim 1.5 \mu \mathrm{m}$ coated on top of a gutter layer based on a rubbery polymer (cross-linked PDMS). For these hollow fiber TFC membranes, both the PAN porous support $\left(\mathrm{CO}_{2}\right.$ permeance $11800 \mathrm{GPU}$ and $\left.\alpha\left(\mathrm{CO}_{2} / \mathrm{N}_{2}\right)=0.8\right)$ and the PDMS-based gutter layer $\left(\mathrm{CO}_{2}\right.$ permeance $5138 \mathrm{GPU}$ and $\left.\alpha\left(\mathrm{CO}_{2} / \mathrm{N}_{2}\right)=10.6\right)$ possessed much lower gas transport properties ${ }^{58}$. By direct deposition of a thin PIM-1 layer on PAN support, it was possible to achieve $\mathrm{CO}_{2}$ permeance of ca. $6600 \mathrm{GPU}$ and $\mathrm{CO}_{2} / \mathrm{N}_{2}$ selectivity of 30 for a PIM-1 layer of $\sim 650 \mathrm{~nm}^{59}$, and 7000 GPU and selectivity of 28 , respectively, for a PIM-1 layer of $\sim 750 \mathrm{~nm}^{57}$. Introduction of $3 \mathrm{wt}$.\% of PEG-functionalized carbon nanotubes (CNT) in the thin selective layer resulted in a remarkable increase of both permeance $(7000 \rightarrow 11000$ GPU) and selectivity $(28 \rightarrow 37.8)^{57}$. It is interesting that it was earlier reported by the same group of authors ${ }^{14}$ that the same content of functionalized CNT $(3 \mathrm{wt} . \%)$ in polymer films of 100-112 $\mu \mathrm{m}$ thickness led to a drop in $\mathrm{CO}_{2}$ permeability of $22.46 \%$, while $\mathrm{CO}_{2} / \mathrm{N}_{2}$ selectivity remained nearly the same for pristine and loaded PIM-1 films at 22.3 and 22.2, respectively. An increase of $\mathrm{CO}_{2}$ permeability of the thick films of up to $181 \%$ was achieved at a lower concentration of functionalized CNT, but the selectivity decreased from 23.9 down to 17.2 with an increase of filler loading in the range of 0.5-2 wt.\%. Such a difference in the performance can be explained by the fact that the subsurface layer would play a noticeable role in the gas performance of the bulk material in the case of a thin film rather than a thick one.

In the present work it should be noted that $\mathrm{CO}_{2}$ and $\mathrm{N}_{2}$ permeance follow the same trends for all samples. However, four samples (TFC\#2, \#4, \#5, \#6) showed very similar permeance of ca. 3000 GPU, despite varying thicknesses of both the X-PTMSP and PIM-1 layers (see Table 2). Two samples (TFC \#1, \#3) demonstrated higher permeance but lower selectivity than other samples (TFC\#5, \#6) of similar X-PTMSP thickness. Such behaviour can be interpreted in terms of a 3-layer structure. For a simple model of three layers, $\mathrm{A}, \mathrm{B}$ and $\mathrm{C}$, in series, with thicknesses $l_{\mathrm{A}}, l_{\mathrm{B}}$ and $l_{\mathrm{C}}$, respectively, of permeabilities $P_{\mathrm{A}}, P_{\mathrm{B}}$ and $P_{\mathrm{C}}$, respectively, we can write:

$$
\frac{l}{P}=\frac{l_{\mathrm{A}}}{P_{\mathrm{A}}}+\frac{l_{\mathrm{B}}}{P_{\mathrm{B}}}+\frac{l_{\mathrm{C}}}{P_{C}}
$$

where $l$ is the total thickness, $P$ is the overall apparent permeability, and the measured permeance is $P / l$. If $\mathrm{A}$ is the $\mathrm{x}$-PTMSP layer, $\mathrm{B}$ is a postulated intermediate, thin, highly selective layer and $\mathrm{C}$ is the PIM-1 layer, we can calculate the permeance, $P_{\mathrm{B}} / l_{\mathrm{B}}$, of the intermediate layer, knowing the thicknesses $l_{\mathrm{A}}$ and $l_{\mathrm{C}}$ for each polymer layer and assuming that $P_{\mathrm{A}}$ and $P_{\mathrm{C}}$ are about 30000 and 6000 Barrer, respectively, for $\mathrm{CO}_{2}$, and 8100 and 320 Barrer, respectively, for $\mathrm{N}_{2}$. To a first approximation we can assume the permeabilities of the bulk polymers are constant, since very close heptane permeability was shown for PIM-1 layers of 0.12 and $30 \mu \mathrm{m}^{60}$.

For the highest permeance sample (TFC\#1) the $\mathrm{CO}_{2}$ permeance (8010 GPU) is consistent with that expected for a 2-layer structure of x-PTMSP and PIM-1 (i.e, if there is an intermediate layer it does not provide additional resistance to $\mathrm{CO}_{2}$ transport). For sample TFC\#3, which has the second highest $\mathrm{CO}_{2}$ permeance (4930 GPU), there is a small effect which can be attributed to an intermediate layer (apparent $\mathrm{CO}_{2}$ permeance $c a$. $13000 \mathrm{GPU}$ ). The other four samples (TFC\#2, \#4, \#5, \#6) all behave as though they have an intermediate layer with $\mathrm{CO}_{2}$ permeance in the range 4000-6000 GPU and $\mathrm{CO}_{2} / \mathrm{N}_{2}$ selectivity in the range 55-88. It is possible that the postulated intermediate layer is associated with the interphase region of about $5 \mathrm{~nm}$ thickness as seen by elemental profiling (Fig. 7f). If a value of $5 \mathrm{~nm}$ is taken for $l_{\mathrm{B}}$ in the simple 3-layer model discussed above, the $\mathrm{CO}_{2}$ permeability of the intermediate layer is in the range 20-30 barrer for samples TFC \#2, \#4, \#5 and \#6. However, current techniques cannot resolve any significant change of atom density in the interphase region and further research is needed to establish methodologies for characterizing subtle differences in polymer packing that may 
influence permeance and selectivity. The thickness of the boundary layer formed in PIM-1 solution after $270 \mathrm{sec}$ of contact with x-PTMSP was estimated as ca. $5 \mu \mathrm{m}$ (see Fig. 10). In the final membrane, after evaporation of all the solvent, the deposited layer might be at least one or two orders of magnitude lower in thickness. Very thin films of a PIM may exhibit enhanced packing, and hence higher selectivity, compared to the bulk polymer. This is illustrated by an anomalous decrease in heptane permeance reported for PIM-1, which appeared to be related to a packing enhancement of the polymer; in particular, a drop by a factor of five was observed when the thickness of the PIM-1 layer was reduced from $140 \mathrm{~nm}$ down to $35 \mathrm{~nm}^{60}$.

\subsection{Aging behavior of TFC membranes}

Despite the very promising performance of the TFC membranes developed in the present work, it should be pointed out that both selective and gutter layers are made of glassy high free volume polymers. The high fractional free volume provides high gas transport properties of these membrane materials, but at the same time the polymers undergo physical aging as a result of partial relaxation of the non-equilibrium free volume structure. Furthermore, thin films based on such materials demonstrate more pronounced physical aging ${ }^{38,61}$ compared with conventional glassy polymers such as polysulfone, polyimide Matrimid or polyphenylene oxide. ${ }^{62}$ Table 5 shows the performance of some of the TFC membranes as-prepared and after three months of storage at ambient conditions. As expected, all samples suffered severely from physical aging, with a 10-40 times drop in $\mathrm{CO}_{2}$ permeance for the aged samples. At the same time, the ideal $\mathrm{CO}_{2} / \mathrm{N}_{2}$ selectivity was nearly the same. The aged membranes possess lower $\mathrm{CO}_{2}$ performance than required for post-combustion capture ${ }^{30}$. However, the mitigation of polymer physical aging with the maintenance of high selectivity would open new potential for applications of polymers of intrinsic microporosity.

Table 5 Performance of as-cast and aged (three months) TFC membranes.

\begin{tabular}{|c|c|c|c|c|}
\hline \multirow{2}{*}{ Sample } & \multirow{2}{*}{ Days } & \multicolumn{2}{|c|}{ Gas permeance, GPU } & \multirow{2}{*}{$\begin{array}{c}\alpha \\
\left(\mathrm{CO}_{2} / \mathrm{N}_{2}\right)\end{array}$} \\
\hline & & $\mathrm{N}_{2}$ & $\mathrm{CO}_{2}$ & \\
\hline \multirow{2}{*}{ TFC\#1 } & 0 & 224 & 8010 & 35.8 \\
\hline & 98 & 6 & 208 & 34.6 \\
\hline \multirow{2}{*}{ TFC\#3 } & 0 & 127 & 4930 & 38.8 \\
\hline & 94 & 8 & 297 & 37.1 \\
\hline \multirow{2}{*}{ TFC\#6 } & 0 & 54 & 3010 & 55.7 \\
\hline & 95 & 5 & 281 & 56.2 \\
\hline
\end{tabular}

Indeed, the physical aging can be partially prevented by restricting the mobility of the polymer chains, thus preserving the polymer structure in time. For example, it was shown ${ }^{18,19}$ that the introduction of porous aromatic framework nanoparticles can prevent the physical aging of dense films of PIMs. However, long-term monitoring of TFC membranes revealed that the presence of PAF nanoparticles in a thin selective layer of PTMSP $(1.5-7 \mu \mathrm{m})$ could not effectively minimize the physical aging compared with the dense films $(30-40 \mu \mathrm{m}) .^{19,38}$ Carbon-based fillers such as carbon nanotubes or carbonized hypercrosslinked polystyrene nanoparticles can also provide promising results in the performance of TFC membranes with PIM-1 over time..$^{29,57,59,63}$ Further research on the mitigation of physical aging in thin films has great interest and potential both from fundamental and practical points of view. Nevertheless, the study of polymer aging was out of the scope of this work, and is a subject of future work. The main goal of this work was to gain an insight into the enhanced selectivity realized in TFC membranes when a cross-linked PTMSP gutter layer is coated with a thin PIM-1 selective layer. 


\section{Conclusions}

A new series of thin film composite membranes (TFC) with high $\mathrm{CO}_{2}$ permeance and $\mathrm{CO}_{2} / \mathrm{N}_{2}$ selectivity was designed and fabricated via coating PIM-1 solution in a mixture of chloroform and trichloroethylene (1:1) on top of a cross-linked PTMSP (x-PTMSP) gutter layer attached to a porous fabric material. By using TEM and SEM analysis, it was shown that there is good integration between the selective PIM-1 $(0.3-0.4 \mu \mathrm{m})$ and gutter x-PTMSP $(1.3-3.4 \mu \mathrm{m})$ layers. All membrane samples demonstrated a strong synergistic enhancement of $\mathrm{CO}_{2} / \mathrm{N}_{2}$ selectivity $(\alpha=35.8-55.7)$ compared to PIM-1 $(\alpha=18.5)$ and cross-linked PTMSP $(\alpha=3.7)$. A number of hypotheses were considered to explain the synergistic effect. Using laser interferometry, the formation of an additional boundary layer in the diffusion region between PTMSP and PIM-1 solution was revealed. This boundary layer arises in the initial stage of the formation of a PIM-1 layer on the PTMSP interface. It is important to note that the boundary layer was much thinner and denser in the case of a solvent mixture, compared with PIM-1 solution in chloroform. We infer that the high selectivity of a multi-layer TFC membrane arises from a thin, dense, highly selective PIM-1 boundary layer generated during coating with the PIM-1 solution in chloroform/trichloroethylene mixture, where trichloroethylene is a poor and less volatile solvent. The as-cast TFC membranes possessed $\mathrm{CO}_{2}$ permeances up to $8000 \mathrm{GPU}$ and $\mathrm{CO}_{2} / \mathrm{N}_{2}$ selectivity up to 55.7, which meet the requirements of optimal membrane properties for postcombustion capture of carbon dioxide ${ }^{30}$ However, the aged TFC membranes showed a severe drop in gas permeance while maintaining nearly the same high selectivity. Thus, future success in the prevention of polymer physical aging, together with the synergy effect in selectivity reported for the first time in this work, will give new opportunities for the application of polymers of intrinsic microporosity.

\section{Conflicts of interest}

There are no conflicts to declare.

\section{Acknowledgements}

This research was supported by the Russian Science Foundation (project No. 18-19-00738). The University of Manchester acknowledges the support of EPSRC (Grants EP/K016946/1, EP/M001342/1 and EP/M01486X/1). Center of collective use "New Petrochemical Processes, Polymer Composites, and Adhesives" for the equipment provided for the research.

\section{References}

1 R. W. Baker, Membrane technology and applications (2nd ed.), John Wiley \& Sons, England, 2004.

2 Y. Yampolskii, Macromol., 2012, 45, 3298-3311.

3 D. F. Sanders, Z. P. Smith, R. Guo, L. M. Robeson, J. E. McGrath, D. R. Paul and B. D. Freeman, Polymer, 2013, 54, 4729-4761.

$4 \quad$ Y. Yampolskii and E. FInkelshtein (ed.), John Wiley \& Sons, England, 2017.

5 L. M. Robeson, J. Membr. Sci., 2008, 320, 390-400.

6 K. Nagai, T. Masuda, T. Nakagawa, B.D. Freeman and I. Pinnau, Prog. Polym. Sci., 2001, 26, $721-798$.

7 N. B. McKeown and P. M. Budd, Chem. Soc. Rev, 2006, 35, 675-683.

8 R. Srinivasan, S. R. Auvil and P. M. Burban, J. Membr. Sci., 1994, 86, 67-86.

9 I. Pinnau and L. G. Toy, J. Membr. Sci., 1996, 116, 199-209.

10 S. Thomas, I. Pinnau, N. Du and M. D. Guiver, J. Membr. Sci., 2009, 338, 1-4.

11 Z. X. Low, P. M. Budd, N. B. McKeown and D. A. Patterson, Chem. Rev., 2018, 118, 5871 5911.

12 Y. P. Yampolskii, L. E. Starannikova and N. A. Belov, Pet. Chem., 2014, 54, 637-651.

13 P. P. Chapala, M. V. Bermeshev, L. E. Starannikova, V. P. Shantarovich, N. N. Gavrilova, V. G. Avakyan, M. P. Filatova, Y. P. Yampolskii and E.S. Finkelshtein, J. Membr. Sci., 2015, 474, 83-91.

14 M. M. Khan, V. Filiz, G. Bengtson, S. Shishatskiy, M. M. Rahman, J. Lillepaerg and V. Abetz, J. Membr. Sci., 2013, 436, 109-120.

15 A. O. Malakhov, E. E. Knyazeva and E. G. Novitsky, Pet. Chem., 2015, 55, 708-715. 
16 C. R. Mason, M. G. Buonomenna, G. Golemme, P. M. Budd, F. Galiano, A. Figoli and V. Hynek, Polymer, 2013, 54, 2222-2230.

17 L. Shao, J. Samseth and M. B. Hägg, J. Membr. Sci., 2009, 326, 285-292.

18 C. H. Lau, P. T. Nguyen, M. R. Hill, A. W. Thornton, K. Konstas, C. M. Doherty, R. J. Mulder, L. Bourgeois, A. C. Y. Liu, D. J. Sprouster, J. P. Sullivan, T. J. Bastow, A. J. Hill, D. L. Gin and R. D. Noble, Angew. Chem., 2014, 126, 5426-5430.

19 A. V. Volkov, D. S. Bakhtin, L. A. Kulikov, M. V. Terenina, G. S. Golubev, G. N. Bondarenko, S. A. Legkov, G. A. Shandryuk, V. V. Volkov, V. S. Khotimskiy, A. A. Belogorlov, A. L. Maksimov and E. A. Karakhanov. J. Membr. Sci., 2016, 517, 80-90.

20 K. V. Otvagina, A. E. Mochalova, T. S. Sazanova, A. N. Petukhov, A. A. Moskvichev, A. V. Vorotyntsev, C. A. M. Afonso and I. V. Vorotyntsev, Membranes, 2016, 6, 31.

21 P. Chapala, M. Bermeshev, L. Starannikova, I. Borisov, V. Shantarovich, V. Lakhtin, V. Volkov and E. Finkelshtein, Macromol. Chem. Phys., 2016, 217, 1966-1976.

22 A. A. Kossov, A. A. Yushkin, V. S. Khotimskiy and A. V. Volkov, Pet. Chem., 2015, 55, 783-790.

23 N. Du, H. B. Park, G. P. Robertson, M. M. Dal-Cin, T. Visser, L. Scoles and M. D. Guiver, Nat. Mater., 2011, 10, 372.

24 I. Pinnau, C. G. Casillas, A. Morisato and B. D. Freeman, J. Polym. Sci., Part B: Polym. Phys., 1996, 34, 2613-2621.

25 W. F. Yong, F. Y. Li, Y. C. Xiao, P. Li, K. P. Pramoda, Y. W. Tong and T. S. Chung, J. Membr. Sci., 2012, 407, 47-57.

26 A. O. Malakhov, G. A. Dibrov, E. G. Litvinova and E. G. Novitsky, Pet. Chem., 2015, 55, 803-809.

27 S. D. Kelman, B. W. Rowe, C. W. Bielawski, S. J. Pas, A. J. Hill, D. R. Paul and B. D. Freeman, J. Membr. Sci., 2008, 320, 123-134.

28 N. Tien-Binh, D. Rodrigue and S. Kaliaguine, J. Membr. Sci., 2018, 548, 429-438.

29 M. Alberto, R. Bhavsar, J. M. Luque-Alled, A. Vijayaraghavan, P. M. Budd and P. Gorgojo, J. Membr. Sci., 2018 563, 513-520.

30 T. C. Merkel, H. Lin, X. Wie and R. Baker, J. Membr. Sci., 2010, 359, 126-139.

31 H. B. Park, J. Kamcev, L. M. Robeson, M. Elimelech and B. D. Freeman, Science, 2017, 356, 6343.

32 J. Peter and K. V. Peinemann, J. Membr. Sci., 2009, 340, 62-72.

33 S. D. Bazhenov, I. L. Borisov, D. S. Bakhtin, A. N. Rybakova, V. S. Khotimskiy, S. P. Molchanov and V. V. Volkov, Green Energy Env., 2016, 235-245.

34 H. Z. Chen, Z. W. Thong, P. Li and T. S. Chung, Int. J. Hydrogen Energy, 2014, 39, 50435053.

35 G. A. Dibrov, V. V. Volkov, V. P. Vasilevsky, A. A. Shutova, S. D.Bazhenov, V. S. Khotimsky and A. V. Volkov, J. Membr. Sci., 2014, 470, 439-450.

36 S. V. Adymkanov, Y. P. Yampolskii, A. M. Polyakov, P. M. Budd, K. J. Reynolds, N. B. McKeown and K. J. Msayib, Polym. Sci. Series A, 2008, 50, 444-450.

37 V. S. Khotimsky, M. V. Tchirkova, E. G. Litvinova, A. I. Rebrov and G. N. Bondarenko, J. Polym. Sci., 2003, A41, 2133-2155.

38 D. S. Bakhtin, L. A. Kulikov, S. A. Legkov, V. S. Khotimskiy, I. S. Levin, I. L. Borisov, A. L. Maksimov, V. V. Volkov, E. A. Karakhanov and A. V. Volkov, J. Membr. Sci., 2018, 554, 211-220.

39 V. Makarova and V. Kulichikhin, InTech Rijeka, 2011, 395.

40 A. Malkin, A. Askadsky, A. Chalykh and V. Kovriga, Experimental methods of polymer physics, Mir Publishers, USSR, 1983.

41 G. B. Vasilyev, M. V. Mironova, E. G. Litvinova, V. V. Volkov, V. S. Khotimskii and V. G. Kulichikhin, Polym. Sci. Series A, 2013, 55, 510-517.

42 S. Tsarkov, V. Khotimsky, P. M. Budd, V. Volkov, J. Kukushkina and A. Volkov, J. Membr. Sci., 2012, 423, 65-72.

43 T. S. Anokhina, A. A. Yushkin, P. M. Budd and A. V. Volkov, Sep. Purif. Technol., 2015, 156, 683-690.

44 A. Yushkin, A. Grekhov, S. Matson, M. Bermeshev, V. Khotimsky, E. Finkelstein, P. M. Budd, V. Volkov, T. J. H. Vlugt and A. Volkov, React. Funct. Polym., 2015, 86, 269-281.

45 M. Cook, P. R. Gaffney, L. G. Peeva and A. G. Livingston, J. Membr. Sci., 2018, 558, $52-$ 63.

46 C. Z. Liang, J. T. Liu, J. Y. Lai and T. S. Chung, J. Membr. Sci., 2018, 563, 93-106.

47 N. Du, G. P. Robertson, J. Song, I. Pinnau and M. D. Guiver, Macromol., 2009, 42, 60386043.

48 N. Du, G. P. Robertson, J. Song, I. Pinnau, S. Thomas and M. D. Guiver, Macromol., 2008, 41, 9656-9662.

49 N. Du, G. P. Robertson, I. Pinnau and M. D. Guiver, Macromol., 2009, 42, 6023-6030.

50 P. M. Budd, N. B. McKeown, B. S. Ghanem, K. J. Msayib, D. Fritsch, L. Starannikova, N. Belov, O. Sanfirova, Y. Yampolskii and V. Shantarovich, J. Membr. Sci., 2008, 325, 851860.

51 P. M. Budd, K. J. Msayib, C. E. Tattershall, B. S. Ghanem, K. J. Reynolds, N. B. McKeown and D. Fritsch, J. Membr. Sci., 2005, 251, 263-269. 
52 E. Lasseuguette, M. C. Ferrari and S. Brandani, Energy Procedia, 2014, 63, 194-201.

53 S. O. Ilyin, V. V. Makarova, T. S. Anokhina, V. Y. Ignatenko, T. V. Brantseva, A. V. Volkov and S. V. Antonov, Cellul., 2018, 25, 2515-2530.

54 J. Crank, The mathematics of diffusion. Second edition, Clarendon Press, England, 1975.

55 A. Mráček, Int. J. Mol. Sci., 2010 11, 532-43.

56 V. V. Makarova, S. V. Antonov, T. V. Brantseva, V. G. Kulichikhin and T. S. Anokhina, Polym. Sci. Ser. A, 2016, 58, 732-743.

57 M. M. Khan, V. Filiz, G. Bengtson, S. Shishatskiy, M. Rahman and V. Abetz, Nano Res. Lett., 2012, 7, 504.

58 C. Z. Liang, W. F. Yong and T. S. Chung, J. Membr. Sci., 2017, 541, 367-377.

59 Y. Huang and D. R. Paul, Polymer., 2004, 45, 8377-8393.

60 P. Gorgojo, S. Karan, H. C. Wong, M. F. Jimenez-Solomon, J. T. Cabral, and A. G. Livingston, Adv. Funct. Mater., 2014, 24, 4729-4737.

61 K. D. Dorkenoo and P. H. Pfromm, Macromol., 2000, 33, 3747-3751.

62 T. Koschine, K. Rätzke, F. Faupel, M. M. Khan, T. Emmler, V. Filiz, V. Abetz, L. Ravelli and W. Egger, J. Polym. Sci., Part B: Polym. Phys., 2015, 53, 213-217.

63. R. S. Bhavsar, T. Mitra, D. J. Adams, A. I. Cooper and P. M. Budd, J. Membr. Sci., 2018, 564, 878-886. 